\section{D) Check for updates}

Cite this: Mater. Adv., 2021, 2,7350

Received 27th August 2021 Accepted 15th October 2021

DOI: 10.1039/d1ma00769f

rsc.li/materials-advances

\title{
Recent advances in silver nanoparticle-based electrochemical sensors for determining organic pollutants in water: a review
}

\author{
Moustafa Zahran, (D) *ab Ziad Khalifa, ${ }^{c}$ Magdy A.-H. Zahran ${ }^{a}$ and \\ Magdi Abdel Azzem ${ }^{a}$
}

\begin{abstract}
Water pollutants have attracted great attention because of their negative effect on human health. Accordingly, various analytical techniques have been investigated to detect water pollutants as a preliminary step for their control. This review highlights silver nanoparticles (AgNPs) as promising electrochemical probes studied for detecting organic pollutants. Electrochemical sensors can be fabricated by modifying electrode surfaces using AgNPs via different techniques, such as electrochemical deposition, drop casting, spin coating, sticking, and transfer sticking, as well as carbon paste-based modification. AgNPs at electrode surfaces can be identified by their stripping to form $\mathrm{Ag}^{+}$with a particular oxidation peak. Additionally, they can be detected indirectly by catalyzing electrochemical reactions. AgNP-modified electrodes are known for their increased surface area and superior conductivity compared with unmodified electrodes. They can detect various inorganic and organic analytes on the basis of the electrochemical responses of the AgNPs or the analyte. The mechanisms of AgNP-modifier-based electrochemical sensors (including AgNPs aggregation, displacement, inhibition, and amplification) and analyte-based electrochemical sensors (including oxidation and reduction) have been highlighted as efficient tools for detecting organic pollutants. Overall, AgNP-based electrochemical sensors are considered a promising tool for determining various organic pollutants in water.
\end{abstract}

${ }^{a}$ Department of Chemistry, Faculty of Science, El-Menoufia University, Shibin El-Kom 32512,Egypt.E-mail: moustafazahran@science.menofia.edu.eg; moustafazahran76@yahoo.com

${ }^{b}$ Menoufia Company for Water and Wastewater, Holding Company for Water and Wastewater, Menoufia 32514, Egypt

${ }^{c}$ Chemical Engineering Department, Faculty of Engineering,

The British University in Egypt, El Sherouk City, 11837, Egypt

\section{Introduction}

Environmental pollution is considered a major worldwide threat to the ecosystem. Water pollution has become the most serious risk among all other pollution types. ${ }^{1}$ The balance of the aquatic ecosystem could be influenced by the presence of

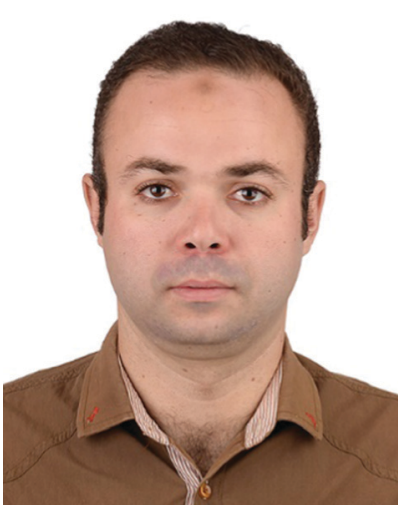

Moustafa Zahran
Moustafa Zahran earned his Bachelor's degree in chemistry (2012) and his Master's degree in organic chemistry (2016) from ElMenoufia University, Shebin ElKom, Egypt. He is a laboratory manager of a surface water treatment plant, Menoufia Company for water and wastewater (MCWW), Holding Company for Water and Wastewater (HCWW), Egypt. His research focuses on the green synthesis of metallic nanoparticles. Currently, he is working on the construction of electrochemical sensors based on metallic nanoparticles to detect organic pollutants, especially pesticides and dyes in surface water.

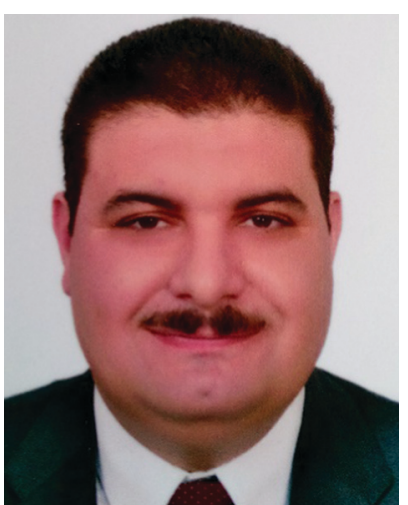

Ziad Khalifa
Ziad Khalifa is currently an Assistant Professor of Physical Chemistry at the British University in Egypt. He has been working for UNEP and EU on many development projects for the assessment and control of pollution in the Mediterranean region and West Asia. His main research interests are in the preparation of novel modified electrodes with applications in biochemical sensors and batteries. His current research activities are in the fields of green chemistry and control of pollution, as well as in the development of new eco-friendly routes for recycling of E-wastes. 
contaminants depending on their concentrations. Contaminants are considered pollutants when they present in higher concentrations that cause harmful effects. Water pollutants include inorganic compounds such as cadmium, mercury, nitrates, and chromium and organic compounds. The effects of these hazardous substances on human health were previously reported. ${ }^{2}$ Accordingly, water treatment to remove organic pollutants has become a vital process. Basically, the treatment can be done by removing pollutants via coagulation and subsequent precipitation, filtration, or adsorption. ${ }^{3-7}$ Additionally, treatment can be achieved by degrading organic pollutants into nonhazardous or less hazardous substances. ${ }^{5}$ As a preliminary step, detecting pollutants is significant before applying suitable treatment processes. In fact, various chromatographic and spectroscopic techniques have been applied for detecting pollutants. ${ }^{89}$ However, they necessitate sophisticated tools and use toxic organic solvents. Recently, optical and electrochemical techniques have been introduced to replace the traditional techniques because of their simplicity, optimized sensitivity, and selectivity. Furthermore, nanoparticles (NPs) have been incorporated into optical and electrochemical sensors for a superior enhancement of their response. ${ }^{10-14}$

NPs have attracted a great attention because of the incredible electrical, magnetic, thermal, and catalytic characteristics that are generated when their particle size is miniaturized. ${ }^{15}$ Their contributions to health, electronics, manufacturing, environment, agriculture, and different biomedical industries have been reported. ${ }^{16,17}$ They can be generally divided into metal-based, metal oxide-based, and carbon-based NPs. Metalbased NPs (MNPs), especially those based on noble metals, have drawn more attention because of their optical, electrical, and sensing characteristics. ${ }^{18-21}$ MNPs can be synthesized via several pathways, such as electrochemical techniques, laser ablation, $\gamma$-radiation, photochemical techniques, and chemical reduction. ${ }^{22}$ They are considered excellent substances for constructing optical and electrochemical sensors. MNP-based optical sensors, which can be divided into colorimetric, fluorometric, and surfaceenhanced Raman scattering sensors, have been broadly applied to detect many analytes, such as metal ions, anions, pesticides, and dyes. ${ }^{20,23-25}$ Also, MNPs can be used as electrochemical probes for determining various inorganic and organic pollutants in water with enhanced sensitivity compared with chromatographic, spectroscopic, and optical techniques. This review highlights silver NPs (AgNPs) as a promising electrochemical probe for detecting organic pollutants in water. The recent advances in the preparation, electrochemical identification and characterization, and role of AgNP-modified electrodes in detecting organic pollutants are also explained.

\section{AgNPs}

AgNPs are among the most frequently used NPs because of their promising catalytic, electronic, chemical, magnetic, optical, and electrochemical properties. ${ }^{22,26,27}$ Various chemical, physical, biological, and mechanical methods are applied in the synthesis of AgNPs. Chemical and biological methods depend on the reduction of $\mathrm{Ag}^{+}$to $\mathrm{Ag}^{\mathrm{O}}$ using suitable reducing agents. Conventional chemical reducing reagents are often toxic and non-biocompatible compounds. Thus, biological reducing agents have been tested as biodegradable and benign compounds for the synthesis of AgNPs. Plants, fungi, and bacteria can be used in the synthesis of AgNPs. ${ }^{26}$ However, AgNPs may require additional capping agents such as polymers for increasing the stability of the nanoparticles. ${ }^{28}$ Accordingly, they were extensively applied in industrial, ${ }^{29}$ biomedical, ${ }^{30,31}$ and environmental applications. ${ }^{32}$ In industrial applications, AgNPs supported on multiwalled carbon nanotubes (MWCNTs), were applied as heterogeneous catalysts to reduce bicarbonate to formate..$^{33}$ This process is used for energy storage and the production of synthetic fuels. Additionally, AgNPs incorporated with graphene oxide NPs in bismuth-doped manganese oxide NPs have been used for oxygen

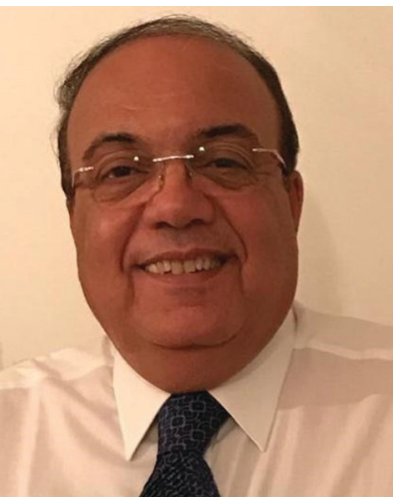

Magdy A.-H. Zahran

Magdy Abdel Hamid Zahran received his BSC (1974) and MSC (1980) degrees from Ain Shams University and his $\mathrm{PhD}$ (1986) degree in chemistry from the Mathematics-Natural Scientific Faculty of Rhenish-FriedrichWilhelm University, Bonn, West Germany. Since 1999, he has been a professor of organic chemistry in the chemistry department, Faculty of Science, Menoufia University, Egypt. He held several postdoctoral research fellowships at Odense University, Denmark and Bonn University, West Germany. His main field of research interest is the development of cancer drugs. Moreover, he is a consultant for many industrial factories in the industrial cities in Egypt.

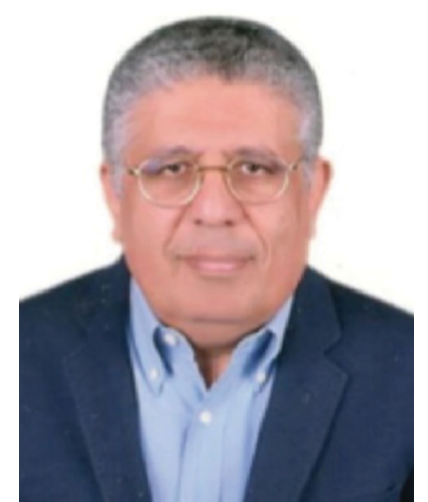

Magdi Abdel Azzem received his BSc (1976) and MSc (1980) degrees from Cairo University and his $P h D$ (1984) degree in chemistry from Cairo University and Joseph Fourier University, Grenoble, France (through the scientific channel system). Since 1995, he has been a professor of electrochemistry in the chemistry department, faculty of science, Menoufia University, Egypt. He was the Chairman of the Chemistry Department (2006-2009) and the Vice Dean for Community and Environmental Development (1998-2001). He was awarded the Prize of the State for the Encouragement (1996) and the Excellence award from Menoufia University (2016). His main fields of research interest are modified electrodes, sensors, and fuel cells. 
reduction reactions and can be applied in clean energy technologies. ${ }^{29}$ Tannic acid-capped AgNPs were used to immobilize $\beta$-galactosidase for its application in food technology. ${ }^{34}$ Moreover, AgNPs stabilized on aluminum oxide provide optical properties of great relevance to the fields of catalysis and photonics. $^{35}$ Recently, AgNPs have gained great attention in the biomedical sector. They have been utilized as key chemotherapeutic drugs to treat various types of cancers, such as pancreatic, prostate, breast, ovarian, and blood cancers. ${ }^{36}$ Additionally, they were previously investigated as potential antibacterial, ${ }^{3-39}$ antifungal, ${ }^{40}$ insecticidal, $^{41}$ and antioxidant ${ }^{30}$ agents. Their contribution in controlling environmental pollution has also been studied. ${ }^{42-45}$ For example, AgNPs prepared using metal-organic framework (MOF) precursors showed high affinity to toxic bromine ions with a high adsorption capacity. ${ }^{32}$ Also, their role in removing pollutants such as total nitrogen, ammonium nitrogen, and total phosphate has been confirmed. ${ }^{42}$ Moreover, they have displayed potential efficiency in degrading some dyes, such as reactive black 5, methyl orange, Congo red, and methylene blue. ${ }^{43-45}$ Recently, Orooji et al. published a review on the recent progress in the degradation and removal of environmental pollutants using AgNPs. ${ }^{5}$ In this study, the detection of environmental pollutants, especially organic ones, using AgNP-based electrochemical sensors has been studied.

\section{AgNPs for detecting organic pollutants}

Organic pollutants comprise a large fraction of water contaminants. Their presence in water harms aquatic organisms and terrestrial life through drinking water. Organic pollutants can be classified into several types, such as pesticides, organic dyes, drugs, nitroaromatics, and mycotoxins. Pesticides are applied in agricultural production to reduce crop damage from pests and weeds. ${ }^{46}$ Organic dyes comprise a large number of complex aromatic compounds that are used in textiles, leather, paints, papers, and plastics. ${ }^{47}$ Pesticides and organic dyes, as environmental pollutants, have attracted major global attention because they are extremely nonbiodegradable and toxic and can transform into carcinogenic, teratogenic, and even mutagenic agents. ${ }^{48}$ Drugs such as antibiotics are widely used to treat bacterial infections in organisms. However, they are considered major organic pollutants in water that cause various health issues, such as immunity decline, allergic reactions, hereditary genetic defects, and cancers. ${ }^{49,50}$ Nitro-aromatics, which are the primary components of explosives, pose several health and environmental problems because of their high water solubility and low vapor pressure. ${ }^{51}$ Mycotoxins, which are secondary metabolites formed by filamentous fungi growing on organic material, are known for their potential threat to human and animal health. ${ }^{52}$ Hence, developing new methods and techniques is necessary as a preliminary step to control organic pollutants.

AgNPs are considered potential nanoprobes for detecting organic pollutants. Recently, they have attracted great attention as optical probes for detecting several organic pollutants because of their strong absorption band, which is very sensitive to the particle size, shape, and relative permittivity of the local environment, in the visible region of light. ${ }^{53}$ AgNP-based optical sensors were reported for the detection of pesticides, ${ }^{20,54-59}$ organic dyes, ${ }^{60}$ drugs, ${ }^{61,62}$ nitro-aromatics, ${ }^{63}$ and mycotoxins. ${ }^{64}$ Electrochemical sensors, such as AgNP-based electrochemical sensors, are considered promising for detecting organic pollutants with sufficient sensitivity and selectivity compared with optical sensors. ${ }^{65}$ Additionally, they are less timeconsuming and easier to set up. In optical sensors, various targeted analytes should be converted into detectible species, while electrochemical sensors can be used for detecting targeted analytes directly. The direct detection of targeted analytes makes electrochemical sensors feasible for in situ studies. Moreover, electrochemical sensors can monitor changes in analyte concentration with time. Thus, AgNP-based electrochemical sensors are studied herein. Fig. 1 shows a schematic of the types of organic pollutants detected using AgNP electrochemical probes. The selected organic pollutants with their classifications and chemical structures are outlined in Table 1.

\section{AgNP-based electrochemical sensors}

Generally, electrochemical sensing systems are based on four main components: a transducer, a capture probe, a reporter probe, and the signal transduction method.

A transducer (electrode) is an element that converts chemical reactions into measurable electrical signals. ${ }^{66}$ Various factors can affect the transduction efficacy, such as the electrode material, kinetics of the redox reaction at the electrode surface, and electrolytic conditions. A redox-active species could be oxidized by donating electrons to the electrode or reduced by receiving electrons from the electrode surface. The oxidized or reduced species are constantly shuttled between the electrode surface and the bulk solution, forming a double layer that behaves like a parallel plate capacitor. ${ }^{66}$

A capture probe is an element that can recognize and bind to targeted analytes. It is usually immobilized directly to

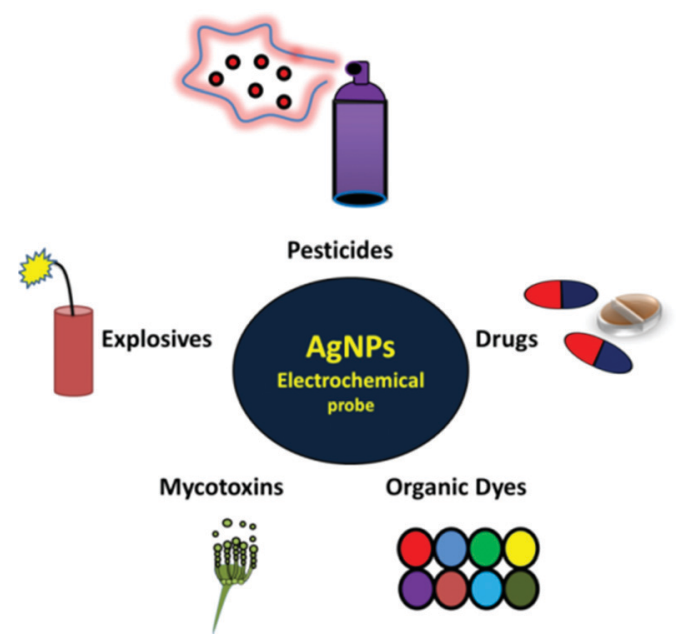

Fig. 1 Schematic of the classes of organic pollutants detected by AgNP electrochemical probes 
Classification and chemical structures of organic pollutants detected by AgNP electrochemical probes

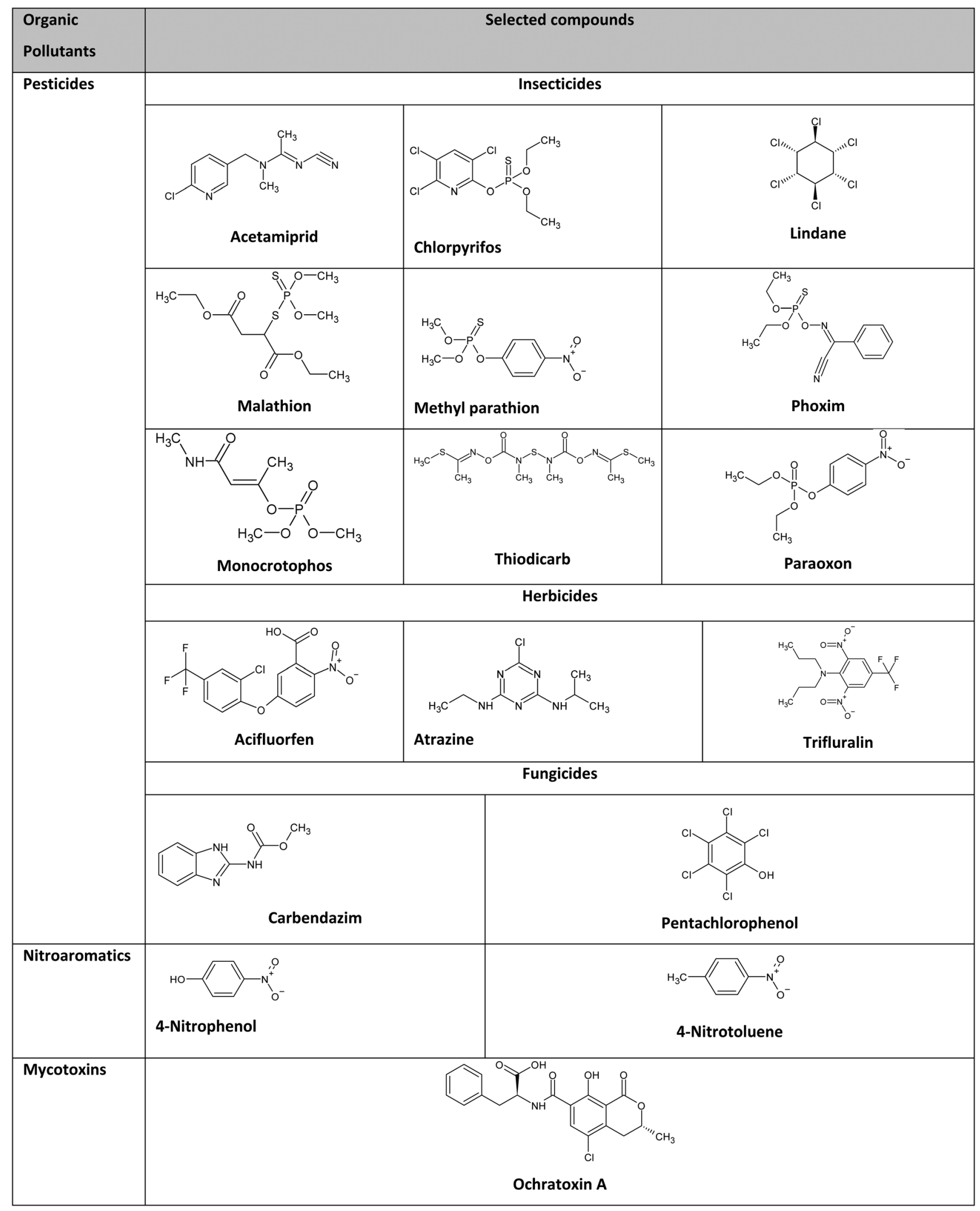


Table 1 (continued)

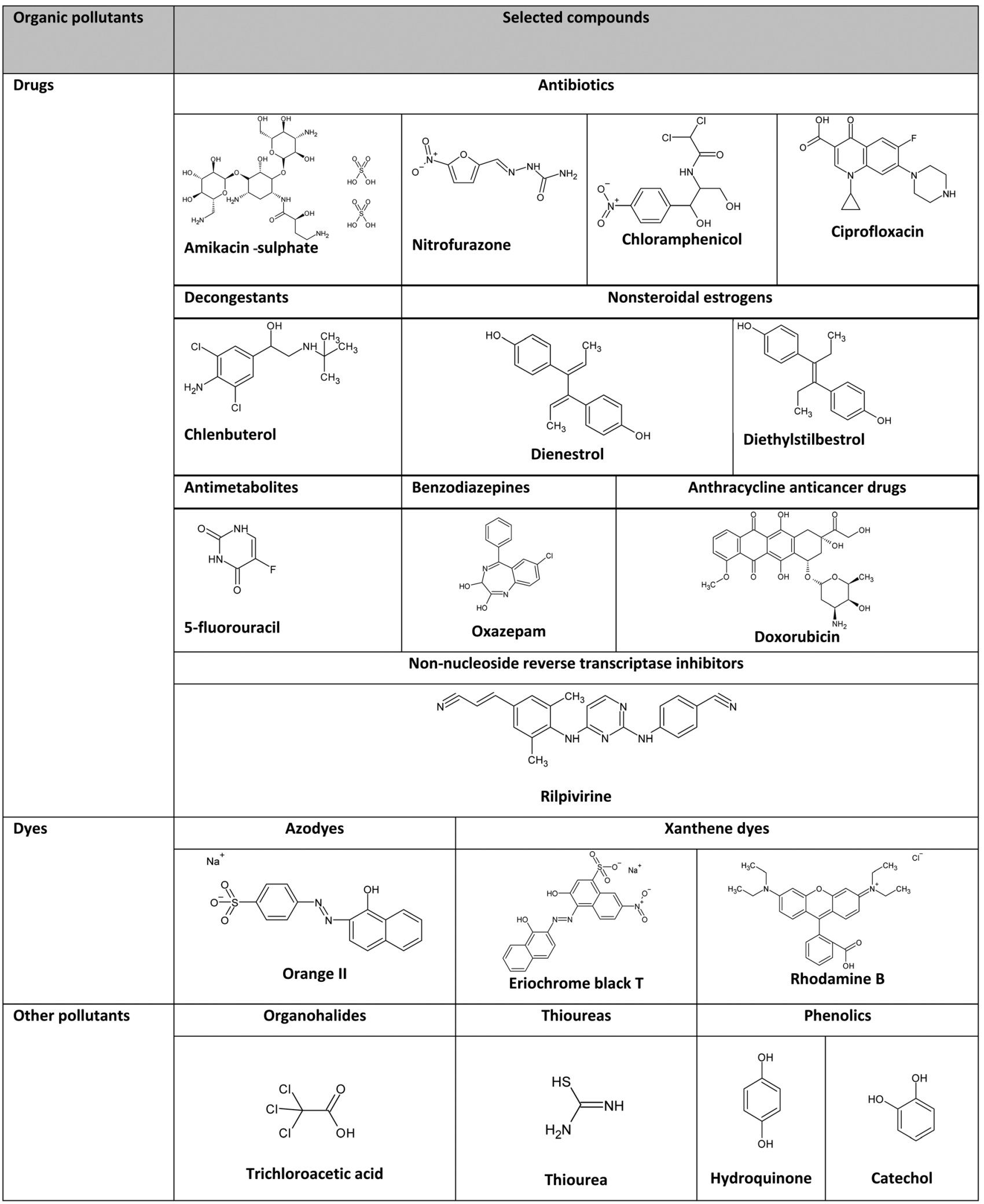

the electrode surface, enhancing its selectivity toward the targeted analytes. ${ }^{67}$ Capture probes can be antibodies, enzymes, nucleic acids aptamers, or molecular imprinted polymers. ${ }^{68}$ 
Antibodies (bioreceptors) act as recognizing elements that can detect specific antigens easily. Thus, antibodies attached to analytes can bind specifically with immobilized antigens, increasing the selectivity toward the analyte of interest. Additionally, antibodies can generate signals which are correlated with the concentration of the targeted analyte. Antibody-based sensors (immunosensors) show advantages such as automation, portability, and the requirement of a low sample volume. ${ }^{69}$ Although there are five classes of antibodies, IgG, IgM, IgA, IgD, and IgE, IgG is the predominant class in human serum. ${ }^{70}$ Thus, IgGs are the most frequently used antibodies in the construction of immunosensors. Moreover, monoclonal and polyclonal antibodies have been used for immunosensing. However, monoclonal antibodies show higher specificity than polyclonal antibodies and are capable of producing an unlimited homogenous type of antibody. ${ }^{71}$

Enzymes are protein macromolecules that can be adsorbed to electrode surfaces to act as receptors for analyte recognition. The use of immobilized enzymes is favorable because of their handling ease, prolonged availability and robustness, increased resistance to environmental changes, and reusability. ${ }^{72}$ The catalytic activity of enzymes is electrochemically monitored through the generation of electroactive enzymatic products. The inhibition of the activity of enzymes by some selected analytes was previously studied for their detection. ${ }^{73}$

Aptamers are oligonucleotide sequences that occur naturally as the sensing part of riboswitches, which are regulatory segments of messenger RNA involved in gene expression. ${ }^{74}$ Synthetic aptamers, which are short single-stranded molecules comprising approximately 20-80 nucleotides with a molecular mass of 6-30 kDa, were introduced as high affinity binders for targeted analytes. ${ }^{75,76}$ Aptamers have attracted great attention among capture probes because of their facile synthesis, low cost, small size, and high stability. ${ }^{77}$ On another note, molecularly imprinted polymers (MIPs) provide specific recognition toward targeted analytes. MIPs could be prepared through the copolymerization of crosslinkers and functional monomers in the presence of template molecules through covalent, noncovalent, and hydrogen bonding. Thereafter, the templates are removed from the MIP films, leaving recognition sites that are complementary to the analytes. ${ }^{78}$ MIPs are preferred over other receptors because of their superior sensitivity, selectivity, and mechanical stability. ${ }^{79}$ Recently, the synergistic effect of a combined aptamer and MIP for analyte recognition has been reported. ${ }^{80}$ The dual recognition element showed the highest selectivity compared with single recognition elements (MIP or aptamer).

A reporter probe is an element that generates a signal in response to analytes. Capture probes such as aptamers and peptides can also be used as reporter probes. ${ }^{81}$ Additionally, other electrode coatings and molecular linkers can be integrated to enhance the sensor performance. ${ }^{82}$

Signal transduction methods, which monitor changes in current or potential resulting from analyte-electrode interactions, include voltammetric, amperometric, and impedimetric methods. ${ }^{83}$ Voltammetric methods include cyclic voltammetry (CV), differential pulse voltammetry (DPV), linear sweep voltammetry, and square wave voltammetry (SWV). ${ }^{84}$ The differences between the voltammetric techniques result from the time waveforms produced by their respective functional applications. ${ }^{85}$ The interpretation of the current-potential-time $(I-E-t)$ relationship ensuing from half-cell reactions at working electrodes is of prime interest in voltammetry. ${ }^{86}$ In the DPV technique, the current is measured at two points for each pulse: before and at the end of the applied pulse. The difference between the two measured currents for each pulse is plotted against the base potential. ${ }^{87}$ In SWV, a special form of DPV, a symmetrical square wave is superimposed on a staircase waveform where the forward pulse coincides with the staircase step. SWV is known for its superior sensitivity and measurement speed compared with the DPV technique. ${ }^{88}$ For greater sensitivity, square wave stripping voltammetry can be applied through the electrodeposition (preconcentration) of specifically targeted analytes, such as metal ions into electrodes, before the SWV analysis. In square wave anodic stripping voltammetry, for example, the deposition (reduction) of metal ions at the electrode surface occurs at a negative potential; then, the reduced species is oxidized (stripped) into the solution again in a positive scan direction. ${ }^{89}$ Differential SWV, a hybrid of DPV and SWV, has been developed to unify the advantages of both techniques. ${ }^{90}$ Adsorptive anodic stripping voltammetry and adsorptive cathodic stripping voltammetry can be used for analyte detection. ${ }^{91}$ The difference between stripping and adsorptive stripping is that the preconcentration in adsorptive stripping is accomplished through accumulation and adsorption on the electrode surfaces under an open circuit potential. ${ }^{92}$

Recently, NPs have been incorporated into electrochemical sensors to optimize the electrode material by increasing the surface area, improving the immobilization efficiency, consolidating the molecular recognition, and enhancing the transduction signals. For example, the immobilization of antibodies at electrode surfaces can be enhanced by incorporating MNPs. ${ }^{93}$ In enzyme-based sensors, NPs can be conjugated with enzymes to increase the sensor sensitivity, stabilize the enzymes, increase the surface area, and enhance conductivity. ${ }^{94}$ The selection of NPs is a critical issue for maintaining enzyme function. ${ }^{95}$ As with the incorporation of antibodies and enzymes, incorporating NPs with aptamers upgrades the immobilization efficiency, the conductivity of the sensing surface, and the signal readout. ${ }^{96}$ Additionally, integrating MIPs with NPs can significantly enhance recognition of target molecules and improve the signal output. ${ }^{97}$ Gold NP (AuNP)- and platinum NP (PtNP)-based electrochemical sensors for detecting analytes were previously reported. ${ }^{98-107}$ In this review, AgNP-based electrochemical sensors for determining analytes are explained. Recent developments in modified electrode fabrication and the mechanisms of organic pollutant detection are also highlighted.

\section{Electrode modification using AgNPs}

AgNPs could be incorporated into electrodes through different in situ and ex situ approaches (Fig. 2). The in situ approach depends on the electrochemical deposition of AgNPs at electrode surfaces through the electrochemical reduction of $\mathrm{Ag}^{+}$ion with subsequent nucleation, aggregation and coalescence of metallic particles (Fig. 2A). Electrochemical deposition is 
- $\mathrm{Ag}^{+}$ion $\bullet \mathrm{Ag}$ atom $2 \mathrm{Aggregated}$ atoms $\bigcirc \mathrm{AgNP} \square$ Electrolyte
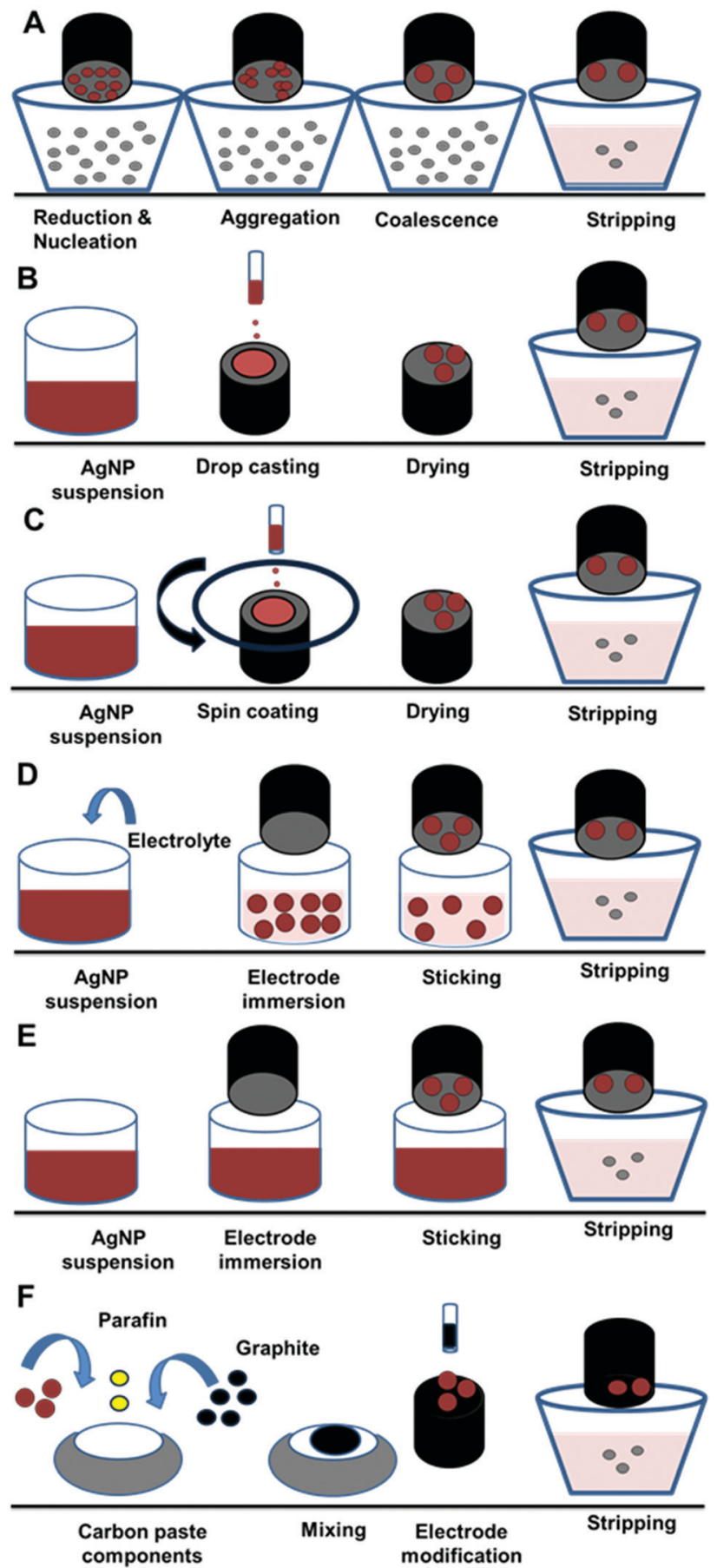

Fig. 2 Electrode modification using AgNPs through electrochemical deposition (A), drop casting (B), spin coating (C), sticking (D), transfer sticking (E), and carbon paste (F), with subsequent AgNP stripping.

considered the most frequently used method for electrode modification. ${ }^{108,109}$ The ex situ approaches include drop casting, spin coating, sticking, transfer sticking, and carbon paste modification. The drop casting technique depends on the placement of AgNPs directly on electrode surfaces with subsequent drying for solvent evaporation ${ }^{110}$ (Fig. 2B). In the spin coating technique (Fig. 2C), AgNPs are directly placed on the surface of a stirring electrode attached to the center of the spin coater via a vacuum system. ${ }^{111}$ In the sticking technique (Fig. 2D), the electrode is dipped in an AgNP suspension mixed with electrolytes for a certain time. ${ }^{110}$ Similarly, the transfer sticking technique is accomplished by dipping the electrode in an AgNP suspension only, which is then transferred to the electrolyte for the stripping process (Fig. 2E). The modified electrode could be prepared by incorporating a paste, formed using AgNPs, paraffin oil, and graphite, into the electrode. ${ }^{112}$

Notably, gold, glassy carbon, and graphite electrodes were mainly used for electrode modification with AgNPs, as shown in Tables 2 and 3. Previously, we studied the efficiency of glassy carbon, gold, and platinum electrodes for immobilizing dissolved organic matter-capped AgNPs on their surfaces. ${ }^{110}$ The efficiency of AgNPs adsorption at the electrode surface was monitored through the detection of the oxidation peak of the AgNPs. Glassy carbon electrode resulted in adherence of a greater amount of AgNPs compared to the other electrodes.

\section{Electrochemical detection and characterization of AgNPs}

Different direct and indirect electrochemical pathways have been reported for the detection of AgNPs at electrode surfaces (Fig. 3). AgNPs can be detected directly through their oxidation (stripping) to form $\mathrm{Ag}^{+}{ }^{+113}$ This pathway requires direct contact between the AgNPs and the electrode surface to enable electron transfer. In some cases, the molecules surrounding AgNPs can prevent electron transfer between the AgNPs and the electrode. Thus, the digestion pathway is followed for the detection. ${ }^{114}$ It is based on digesting AgNPs into $\mathrm{Ag}^{+}$using a strong oxidant. Then, the released ions are deposited on the electrode surface, followed by stripping to $\mathrm{Ag}^{+}$, showing the AgNP oxidation peak. The AgNP stripping peak can be improved by catalyzing AgNP oxidation using enhancers such as AuNPs. ${ }^{115}$ Moreover, AgNPs can be detected indirectly through catalyzing an electrochemical reaction. ${ }^{116}$

Customarily, CV and electrochemical impedance spectroscopy (EIS) are used to characterize AgNP-modified electrodes. In both techniques, ferrocyanide ions $\left(\left[\mathrm{Fe}(\mathrm{CN})_{6}\right]^{3-/ 4-}\right)$ are used as a redox probe. As Fig. 4 shows, the $\mathrm{CV}$ and Nyquist plots of the bare and AgNP-modified electrodes were obtained. The CV measurements show an enhancement in the oxidation peak current and a decrement in the oxidation/reduction peak separation. In the Nyquist plots, the electron transfer resistance $\left(R_{\mathrm{CT}}\right)$, which is equal to the semicircle diameter of EIS, decreased after electrode modification using AgNPs. The improvement in the oxidation peak current and the diminution of the $R_{\mathrm{CT}}$ are attributed to the role of AgNPs in the enhancing the electron transfer rate between the redox probe and the electrode surface, and hence in the decrement of charge transfer resistance for the redox probe to access the electrode. ${ }^{117}$ On another note, the redox behavior of AgNPs in phosphate buffer solution was characterized by CV. ${ }^{10-14}$ The CV diagram shows the oxidation and reduction peaks of the AgNPs at the electrode surface. The oxidation peak corresponds to the conversion of $\mathrm{Ag}^{0}$ to $\mathrm{Ag}^{+}$on the forward anodic scan, while the reduction peak corresponds to the conversion of $\mathrm{Ag}^{+}$back to 
Table 2 AgNP-based electrochemical sensors

\begin{tabular}{|c|c|c|c|c|c|c|}
\hline Analyte & AgNPs-modified electrode & $\begin{array}{l}\text { Modification } \\
\text { technique }\end{array}$ & Technique & Mechanism & $\begin{array}{l}\text { Detection } \\
\text { limit (nM) }\end{array}$ & Ref. \\
\hline $\begin{array}{l}\text { Amyloid- } \beta \text { oligomers } \\
\text { (A } \beta \text { Os) }\end{array}$ & $\begin{array}{l}\text { AgNPs/Ad-PrP(95-110)/MCH/ } \beta \text { - } \\
\text { CD/Au electrode }\end{array}$ & $\begin{array}{l}\text { Soaking } \\
\text { (sticking) }\end{array}$ & LSV & $\begin{array}{l}\text { Modifier-based sensing (aggregation } \\
\text { with signal inhibition) }\end{array}$ & 0.008 & 151 \\
\hline Caffeine & rGO-AgNPs/PG & $\begin{array}{l}\text { Electrochemical } \\
\text { deposition }\end{array}$ & SWV & Analyte-based sensing (oxidation) & 0.54 & 149 \\
\hline Creatinine & AgNPs/MCNT/FA/CPE & Carbon paste & DPV & Analyte-based sensing (oxidation) & 8 & 112 \\
\hline DNA & $\begin{array}{l}\mathrm{PNA} / \mathrm{MCH} / \mathrm{T}-\mathrm{DNA} / \mathrm{Zr}^{4+} / \mathrm{BPAA} / \\
\text { GEMA/NaIO } \\
4 / \mathrm{AgNPs} / \mathrm{Au} \text { electrode }\end{array}$ & $\begin{array}{l}\text { Soaking } \\
\text { (sticking) }\end{array}$ & DPV & $\begin{array}{l}\text { Modifier-based sensing } \\
\text { (amplification) }\end{array}$ & $4.725 \times 10^{-9}$ & 119 \\
\hline Estriol & rGO-AgNPs/GC & Drop casting & DPV & Analyte-based sensing (oxidation) & 21 & 148 \\
\hline Gastrodin & MIPs/rGO-AgNPs/NF & $\begin{array}{l}\text { Electrochemical } \\
\text { deposition }\end{array}$ & DPV & Modifier-based sensing (inhibition) & 1 & 147 \\
\hline Glucose & Mucilage-AgNPs/GC & $\begin{array}{l}\text { Transfer- } \\
\text { sticking }\end{array}$ & SWV & Modifier-based sensing (inhibition) & $100 \times 10^{3}$ & 113 \\
\hline Gonadotropin & AgNPs/peptide/Au electrode & $\begin{array}{l}\text { Soaking } \\
\text { (sticking) }\end{array}$ & LSV & $\begin{array}{l}\text { Modifier-based sensing (aggregation } \\
\text { with signal amplification) }\end{array}$ & $0.0004\left(\mathrm{U} \mathrm{mL}^{-1}\right)$ & 143 \\
\hline Influenza virus $\mathrm{H7}$ & $\begin{array}{l}\text { Antibody-AgNPs-graphene/Au } \\
\text { electrode }\end{array}$ & Drop casting & LSV & $\begin{array}{l}\text { Modifier-based sensing } \\
\text { (amplification) }\end{array}$ & $0016(\mathrm{ppb})$ & 145 \\
\hline NS1 biomarker & Antibody-AgNPs/GPE & $\begin{array}{l}\text { Soaking } \\
\text { (sticking) }\end{array}$ & DPV & $\begin{array}{l}\text { Modifier-based sensing } \\
\text { (amplification) }\end{array}$ & $0.5(\mathrm{ppb})$ & 142 \\
\hline p53 protein & $\begin{array}{l}\text { BDT-AgNPs/p53/dsDNA/Au } \\
\text { electrode }\end{array}$ & $\begin{array}{l}\text { Soaking } \\
\text { (sticking) }\end{array}$ & LSV & $\begin{array}{l}\text { Modifier-based sensing } \\
\text { (amplification) }\end{array}$ & 0.0001 & 144 \\
\hline T4 PNK & $\begin{array}{l}\text { AgNPs/T4 DNA ligase/DNA probe/ } \\
\text { T4 PNK/DNA probe/Au electrode }\end{array}$ & $\begin{array}{l}\text { Soaking } \\
\text { (sticking) }\end{array}$ & LSV & $\begin{array}{l}\text { Modifier-based sensing } \\
\text { (amplification) }\end{array}$ & $0.01\left(\mathrm{U} \mathrm{mL} \mathrm{L}^{-1}\right)$ & 146 \\
\hline
\end{tabular}

$\mathrm{Ag}^{0}$ on the reverse cathodic scan. ${ }^{13}$ The potential and current values of the oxidation peak of AgNPs provide valuable information about the size and amount of AgNPs adsorbed at the surface of the electrodes. ${ }^{10}$

\section{Mechanisms of AgNP-based electrochemical sensors}

AgNP-based electrochemical sensors are considered a promising tool for analyte detection with low cost and high sensitivity. AgNP-modified electrodes can be used to detect analytes on the basis of the modifier and the electrochemical responses of the analyte. Modifier-based sensors involve the aggregation, inhibition, amplification, and displacement of AgNPs after analyte addition. By contrast, analyte-based sensors depend on the oxidation or reduction of the analyte itself (Fig. 5). The aggregation, inhibition, amplification, and displacement mechanisms depend on the analyte and capping agent of the AgNPs. Fig. 6 shows that modifier-based sensors lead to signal inhibition, signal amplification, or signal inhibition/amplification. According to the electrochemical transduction method, AgNP-based electrochemical sensors can be classified into voltammetric, amperometric, chronoamperometric, and impedimetric sensors.

Voltammetric sensors are versatile tools that can be utilized for monitoring signal inhibition, signal amplification, and signal inhibition/amplifications, related to the aggregation, inhibition, amplification, and displacement mechanisms. ${ }^{47,110,118,119}$ In amperometric and chronoamperometric sensors, the current produced from the oxidation or reduction of specific electroactive species is measured at constant voltage. ${ }^{120-123}$ The current is plotted against time in the amperograms and chronoamperograms. Previously, amperometry was studied as an analyte-based electrochemical technique using AgNPs as electrode modifiers. ${ }^{124-127}$
Similarly, chronoamperometry was studied as both an analyte and a modifier-based electrochemical technique using AgNP modifiers. ${ }^{128,129}$ In impedimetric sensors, the concentration of the analyte in solution is determined by measuring the number of bound molecules on the receptors immobilized on the electrode surface; this leads to increased resistance accompanied by an amplification signal or decreased resistance accompanied by an inhibition signal, depending on the chemistry of the targeted analyte. ${ }^{117,130,131}$ AgNPs can be incorporated into the electrode surface to increase the electron transport. ${ }^{132}$ Overall, AgNPs can be used as a catalyst in analyte-based electrochemical sensors or as a probe in modifier-based electrochemical sensors. ${ }^{124,126,127,133-141}$ Table 2 lists the recently reported AgNPmodified electrodes for detecting different organic analytes using different sensing mechanisms and transduction techniques. AgNP aggregation-based electrochemical sensors were reported for determining amyloid- $\beta$ oligomers (AßOs) and gonadotropins. ${ }^{142,143}$ Additionally, electrochemical sensors based on AgNP oxidation amplification and inhibition were used to assess T4 PNK, p53 protein, biomarker NS1, influenza virus H7, gastrodin, glucose, and DNA. ${ }^{113,119,142,144-147}$ Moreover, analyte-based electrochemical sensors using AgNPs as electrode modifiers were used to detect caffeine, creatinine, glucose, and estriol. ${ }^{112,148-150}$

\section{AgNP-based electrochemical sensors for detecting organic pollutants}

\section{Electrochemical sensors based on aggregation of AgNPs}

Colorimetric sensors based on the aggregation of MNPs for analyte determination can be converted into enhanced 
Table 3 AgNP-based electrochemical sensors for detecting organic pollutants

\begin{tabular}{|c|c|c|c|c|c|c|}
\hline Organic pollutant & Sensing material & $\begin{array}{l}\text { Modification } \\
\text { technique }\end{array}$ & Technique & Mechanism & LOD (nM) & Ref. \\
\hline Acetamiprid & AgNPs/His-GQD/GC & Drop casting & DPV & Modifier-based sensing (inhibition) & $4.0 \times 10^{-8}$ & 155 \\
\hline Acifluorfen & $\mathrm{FeS}_{2} / \mathrm{AgNPs} / \mathrm{SPCE}$ & Drop casting & DPV & Analyte-based sensing (reduction) & 2.5 & 164 \\
\hline Amikacin sulphate & rGO-AgNPs/Ni foam electrode & & DPV & Analyte-based sensing (oxidation) & 38 & 106 \\
\hline Atrazine & DOM-AgNPs/GC & Transfer sticking & SWASV & $\begin{array}{l}\text { Modifier-based sensing } \\
\text { (aggregation) } \\
\text { Analyte-based sensing (oxidation) }\end{array}$ & $\begin{array}{l}89.35 \\
63.01\end{array}$ & 110 \\
\hline Carbendazim & Fumed silica@AgNPs/CPE & Carbon paste & DPV & Analyte-based sensing (oxidation) & 0.94 & 171 \\
\hline Catechol & TACoPc/PANI/AgNPs/GC & Drop casting & DPV & Analyte-based sensing (oxidation) & 460 & 177 \\
\hline Chloramphenicol & Apt/AgNP/[ $\left.\mathrm{NH}_{2}-\mathrm{Si}\right]-\mathrm{f}-\mathrm{GO} / \mathrm{GC}$ & Drop casting & DPV & Modifier-based sensing (inhibition) & 0.0033 & 156 \\
\hline Chlorpyrifos & $\begin{array}{l}\text { DOM-AgNPs/GC } \\
\text { Natural latex-AgNPs/GC } \\
\text { Mucilage-AgNPs/GC }\end{array}$ & Sticking & SWV & Modifier-based inhibition & $\begin{array}{l}136.9 \\
87 \\
0.048\end{array}$ & 118 \\
\hline Ciprofloxacin & AgNPs-AuNPs/Au electrode & Drop casting & DPV & Analyte-based sensing (oxidation) & 7.24 & 135 \\
\hline Clenbuterol & Melamine-AgNPs/Au electrode & $\begin{array}{l}\text { Soaking } \\
\text { (sticking) }\end{array}$ & LSV & $\begin{array}{l}\text { Modifier-based sensing } \\
\text { (amplification) }\end{array}$ & 0.01 & 161 \\
\hline Dienesterol & AgNPs/SWCNT/CPE & Carbon paste & SWV & Analyte-based sensing (oxidation) & 43.55 & 172 \\
\hline Doxorubicin & Poly(chitosan)/AgNPs/GC & $\begin{array}{l}\text { Electrochemical } \\
\text { deposition }\end{array}$ & SWV & Analyte-based sensing (oxidation) & 103 & 178 \\
\hline $\begin{array}{l}\text { Diethylstilbestrol } \\
\text { (DES) }\end{array}$ & $\begin{array}{l}\alpha-\mathrm{Fe}_{2} \mathrm{O}_{3}-\mathrm{BSA}-\mathrm{DES} / \mathrm{DES} / \mathrm{BSA} / \mathrm{Ab} / \\
\mathrm{Cu}_{3}(\mathrm{BTC})_{2}-\mathrm{Ag} \text { NPs/GC }\end{array}$ & Drop casting & LSV & $\begin{array}{l}\text { Modifier-based sensing } \\
\text { (amplification) }\end{array}$ & $0.00167 \mathrm{ppb}$ & 160 \\
\hline Eriochrome black T & Natural latex-AgNPs/GC & Transfer-sticking & SWV & Electrochemical displacement & $\begin{array}{l}15.2 \\
\text { (modifier) } \\
6.33 \\
\text { (displacer) }\end{array}$ & 47 \\
\hline 5-Fluorouracil & Porphyran-AgNPs/CPE & Carbon paste & SWV & Analyte-based sensing (oxidation) & 10700 & 173 \\
\hline Hydroquinone & TACoPc/PANI/AgNPs/GC & Drop casting & DPV & Analyte-based sensing (oxidation) & 600 & 177 \\
\hline Lindane & AgNPs-PANI-Nano-ZSM-5 & Drop casting & DPV & Analyte-based sensing (reduction) & 5 & 163 \\
\hline Malathion & ACHE/AgNPs@ $\mathrm{Ti}_{3} \mathrm{C}_{2} \mathrm{~T}_{x} / \mathrm{GC}$ & Drop casting & DPV & Modifier-based sensing (inhibition) & $0.327 \times 10^{-5}$ & 158 \\
\hline Methyl parathion & $\begin{array}{l}\text { para-Sulfonatocalix[6]arene- } \\
\text { AgNPs/GC }\end{array}$ & $\begin{array}{l}\text { Electrochemical } \\
\text { deposition }\end{array}$ & DPV & Analyte-based sensing (reduction) & 4 & 165 \\
\hline Methylene blue & Gum arabic-AgNPs/GC & Sticking & SWASV & $\begin{array}{l}\text { Modifier-based sensing } \\
\text { (amplification) } \\
\text { Analyte-based sensing (oxidation) }\end{array}$ & 200 and 1375 & 28 \\
\hline Monocrotophos & $\begin{array}{l}\mathrm{AChE} / \mathrm{CNTs}-\mathrm{NH}_{2} / \mathrm{Ag} \text { NPs-N-F- } \\
\mathrm{MoS}_{2} / \mathrm{GC}\end{array}$ & Drop casting & DPV & Modifier-based sensing (inhibition) & 0.0002 & 159 \\
\hline 4-Nitrophenol & $\begin{array}{l}\beta \text {-1,4-Poly D-glucosamine-AgNPs/ } \\
\text { graphite electrode }\end{array}$ & $\begin{array}{l}\text { Soaking } \\
\text { (sticking) }\end{array}$ & DPV & Analyte-based sensing (reduction) & 600 & 128 \\
\hline 4-Nitrotoluene & AgNPs/Au electrode & Drop casting & Amperometry & Analyte-based sensing (reduction) & 92 & 125 \\
\hline Nitrofurazone & $\mathrm{BC} / \mathrm{Cr}_{2} \mathrm{O}_{3} / \mathrm{Ag} / \mathrm{MIP} / \mathrm{GC}$ & Drop casting & DPV & Analyte-based sensing (reduction) & 3 & 166 \\
\hline Ochratoxin A & $\begin{array}{l}\mathrm{Pt}-\mathrm{Ag} \text { NPs/PCN-223-Fe/gold } \\
\text { electrode }\end{array}$ & Drop casting & DPV & Modifier-based sensing (inhibition) & 34.7 & 157 \\
\hline Orange II & Carbamazepine-AgNPs/GC & Drop casting & DPV & Analyte-based sensing (oxidation) & 1.2 & 176 \\
\hline Oxazepam & $\mathrm{Ag}-\mathrm{Pt} / \mathrm{GRs} / \mathrm{GC}$ & Drop casting & DPV & Analyte-based sensing (reduction) & 42 & 170 \\
\hline Paraoxon & Stearic acid/AgNPs/GC & $\begin{array}{l}\text { Electrochemical } \\
\text { deposition }\end{array}$ & DPV & Analyte-based sensing (reduction) & 0.1 & 167 \\
\hline Pentachlorophenol & AgNPs-rGO/GC & Drop casting & DPV & Analyte-based sensing (oxidation) & 1 & 175 \\
\hline Phoxim & AChE@CChit/AgNPs/rGO/GC & Drop casting & DPV & Modifier-based sensing (inhibition) & 0.000081 & 82 \\
\hline Rhodamine B & Carbamazepine-AgNPs/GC & Drop casting & DPV & Analyte-based sensing (oxidation) & 1 & 176 \\
\hline Rilpivirine & CQDs/NH ${ }_{2}$-fMWCNT/AgNPs/GC & Drop casting & DPAdSV & Analyte-based sensing (oxidation) & 0.03 and 0.06 & 174 \\
\hline Thiodicarb & AgNPs/SAE & & SWAdSV & Analyte-based sensing (reduction) & 20.3 & 168 \\
\hline Thiourea & Oxadiazole/AgNPs/GC & $\begin{array}{l}\text { Electrochemical } \\
\text { deposition }\end{array}$ & DPV & Analyte-based sensing (oxidation) & 0.1 & 129 \\
\hline Trichloroacetic acid & Maleic acid-AgNPs/GC & Drop casting & SWV & Analyte-based sensing (reduction) & 30 & 169 \\
\hline Trifluralin & rGO-PEI-AgNPs/GC & $\begin{array}{l}\text { Electrochemical } \\
\text { deposition }\end{array}$ & $\begin{array}{l}\text { SWV and } \\
\text { DPV }\end{array}$ & $\begin{array}{l}\text { Modifier-based sensing } \\
\text { (amplification) }\end{array}$ & 1 & 162 \\
\hline
\end{tabular}

His-GQD: histidine-functionalized graphene quantum dots, GC: glassy carbon, DPV: differential pulse voltammetry, SPCE: screen-printed carbon electrode, rGO: reduced graphene oxide, SWASV: square wave anodic stripping voltammetry, CPE: carbon paste electrode, TACoPc: tetra amino cobalt phthalocyanine, PANI: polyaniline, [ $\mathrm{NH}_{2}$-Si]-f-GO: graphene oxide functionalized with (3-aminopropyl)triethoxysilane, DOM: dissolved organic matter, SWV: square wave voltammetry, LSV: linear sweep voltammetry, SWCNT: single-walled carbon nanotubes, BSA: bovine serum albumin, DES: diethylstilbestrol, PANI-Nano-ZSM-5: nanoporous polyaniline-zeolite, ACHE: acetylcholinesterase, MIB: molecular imprinted polymer, GRs: graphene nanosheets, CChit: carboxylic chitosan, CQDs: carbon quantum dots, $\mathrm{NH}_{2}$-fMWCNT: amine-functionalized multiwalled carbon nanotubes, DPAdSV: differential pulse adsorptive stripping voltammetry, SWAdV: square wave adsorptive voltammetry, SAE: solid amalgam electrode, PEI: polyethylene imine.

electrochemical sensors. ${ }^{65}$ In contrast to the colorimetric assay, electrochemical aggregation of MNPs results in voltammetric signal inhibition, amplification, or inhibition/amplification of
MNPs oxidation, depending on the analyte and capping agents of the MNPs. ${ }^{65,110,151,152}$ For example, an electrochemical aggregation sensor based on the inhibition of AgNP signals was 


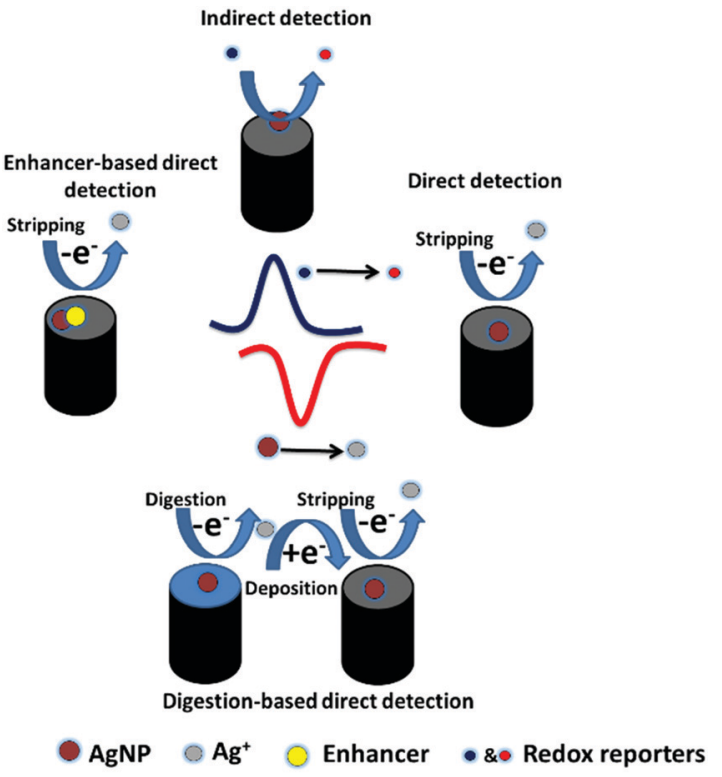

Fig. 3 AgNP electrochemical detection techniques.

A

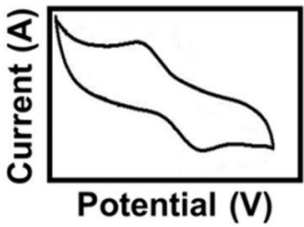

B

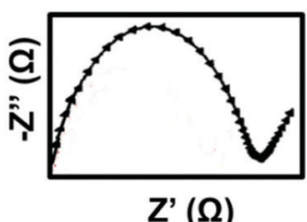

$\mathbf{Z}^{\prime}(\mathbf{\Omega})$
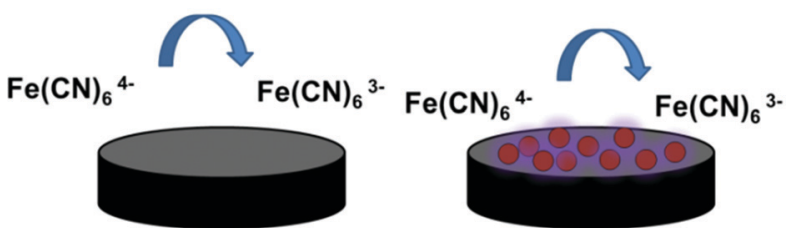

Fig. 4 Schematic of the CV (A) and EIS Nyquist (B) plots of bare and AgNP-modified electrodes.

constructed previously to detect A $\beta O$ s. $^{151}$ Adamantine (Ad)labeled $\operatorname{PrP}(95-110)$ was used as a receptor to induce the aggregation of AgNPs. Ad-PrP(95-110) interacts specifically with A $\beta$ Os, thus losing its capability to bind AgNPs and induce the formation of an AgNP-based network on the electrode surface, leading to a decrease in the current signal. On a different note, an electrochemical thymine-functionalized AgNP aggregation sensor based on AgNP current signal amplification was studied. ${ }^{6,143}$ The third type of electrochemical aggregation sensor is based on signal inhibition/amplification, where the nonaggregated AgNPs signal is inhibited and the aggregated

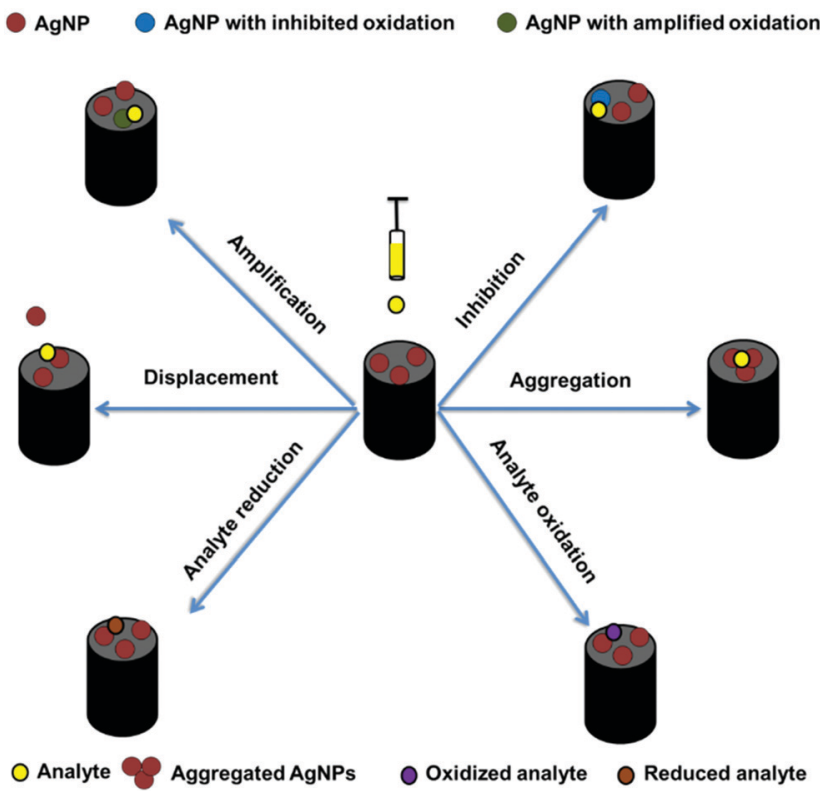

Fig. 5 Types of AgNP-based electrochemical sensors.

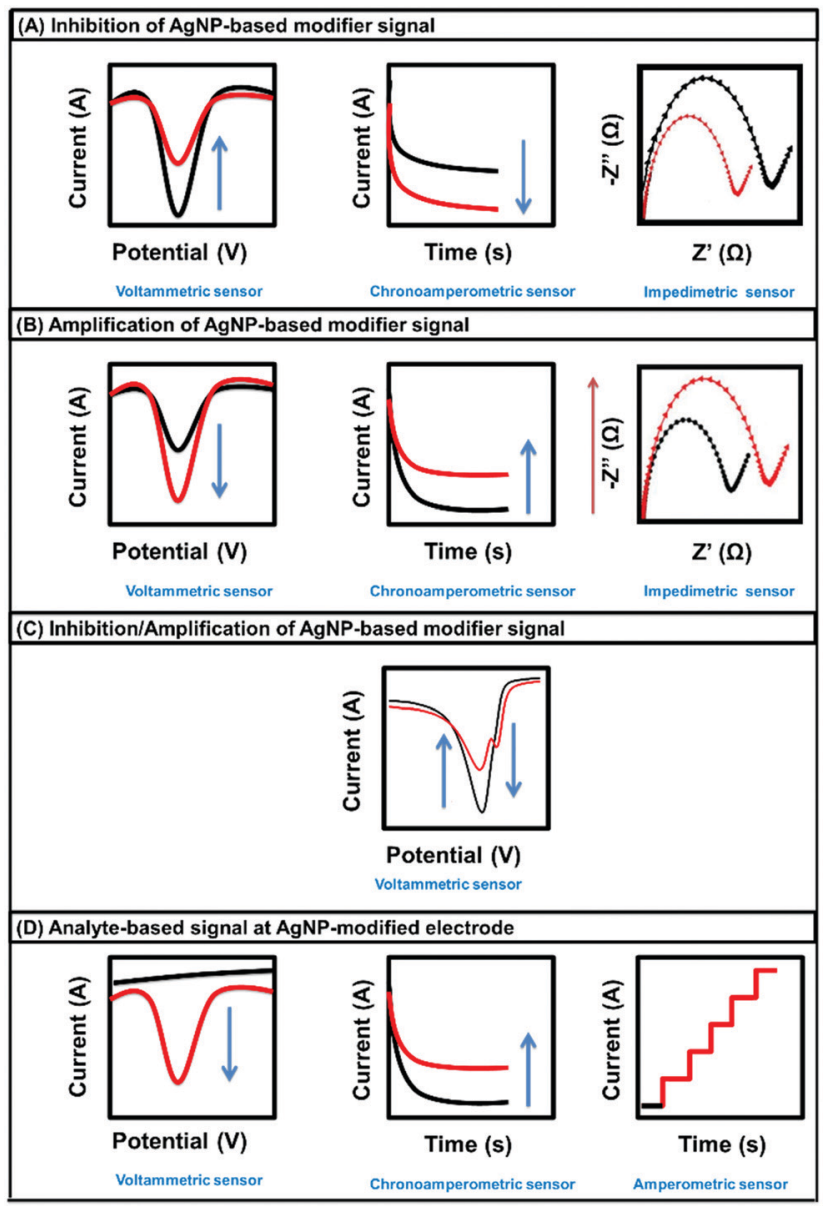

Fig. 6 Electrochemical responses of AgNP-based modifier signals (A-C) and analyte-based signals (D) before (black line) and after (red line) the addition of analyte. 
AgNPs signal, with a positive potential shift, is amplified. ${ }^{110}$ The positive potential shift after the induced AgNPs aggregation is attributed to the diminished surface area to volume ratio. ${ }^{153,154}$ Our research group previously reported a dissolved organic matter (DOM)-capped AgNP aggregation-based electrochemical sensor to determine atrazine herbicide in natural water. ${ }^{110}$ Atrazine was detected on the basis of the inhibition of the nonaggregated AgNPs signal and the amplification of the aggregated AgNPs signal after atrazine addition (Table 3).

\section{Electrochemical sensors based on displacement of AgNPs}

Electrochemical displacement sensors are considered a promising tool for analyte detection with high sensitivity and selectivity. To the best of our knowledge, only two studies have reported electrochemical displacement sensors for analyte detection. The first study showed the capability of $\mathrm{Hg}^{2+}$ to replace measurable amounts of AgNPs at glassy carbon to indirectly detect $\mathrm{Hg}^{2+}$ in water. ${ }^{140}$ The electrochemical displacement mechanism is based on the interaction between $\mathrm{Hg}^{2+}$ and AgNPs before the AgNPs stripping process that results in the conversion of $\mathrm{AgNPs}$ to $\mathrm{Ag}^{+}$by $\mathrm{Hg}^{2+}$. This conversion reduces the amount of AgNPs, which reflects the $\mathrm{Hg}^{2+}$ concentration in the solution. In the stripping process, there was a reduction in the stripping peak of AgNPs that remained unreacted with $\mathrm{Hg}^{2+}$. The second study was conducted by our research group to develop an electrochemical sensor for the detection of Eriochrome black T (EBT) dye in water using natural latex (NL) polymer-capped AgNPs. ${ }^{47}$ The displacement mechanism is based on the affinity of EBT to be oxidized and polymerized at the modified electrode compared with that of NL-AgNP. The displacement of the NL-AgNPs was accompanied by a decrease in the stripping peak of the AgNPs. Additionally, the oxidation peak of EBT increased after the displacement, resulting in a two-way sensor. Thus, electrochemical displacement sensors are considered promising for detecting many inorganic and organic molecules.

\section{Electrochemical sensors based on oxidation/reduction inhibition of AgNPs}

The electron transfer inhibition of AgNP-based modifiers leads to voltammetric signal inhibition or impedimetric signal amplification. Previously, a DPV sensor was reported for the detection of acetamiprid insecticide based on its inhibitory effect on the AgNP-based modifier response. ${ }^{155}$ For the selective detection of acetamiprid, an aptamer of acetamiprid was connected to the AgNPs via a sulfur linkage. ${ }^{155}$ Similarly, chloramphenicol was detected on the basis of the inhibition of the aptamer/AgNP-based modifier signal. ${ }^{156}$ Moreover, ochratoxin A, a mycotoxin, was detected through the inhibition of the oxygen reduction signal. ${ }^{157}$ First, AgNPs were incorporated with PtNPs and iron-porphyrinic MOF for large catalytic enhancement of oxygen reduction. Then, the oxygen reduction signal was inhibited by the aptamer bounded by ochratoxin A. Additionally, acetylcholinesterase (AChE) biosensors were developed to detect phoxim and malathion insecticides via enzyme inhibition at the GC electrode. ${ }^{82,158}$ The AgNPs not only enhanced the electron transfer but also increased the electrode surface area. Similarly, AgNPs-N-F-MoS ${ }_{2}$ nanocomposites, coupled with AChE inhibition, were used to detect monocrotophos. ${ }^{159}$ Recently, we reported an AgNP-based electrochemical inhibition method to detect chlorpyrifos in natural water without the need to use aptamers or enzymes. ${ }^{118}$ Three GC electrodes modified using DOM-AgNPs, NL-AgNPs and mucilage-AgNPs were used for chlorpyrifos sensing. ${ }^{118}$ The detection mechanism is based on the role of pesticides in the inhibition of oxidation of AgNPs.

\section{Electrochemical sensors based on oxidation/reduction amplification of AgNPs}

The electron transfer enhancement of AgNP-based modifiers is accompanied by voltammetric signal amplification or impedimetric signal inhibition. The voltammetric signal amplification of MNP-based modifiers could be obtained by enriching the effect of MNPs without aggregating them. The signal amplification of the AgNPs was studied to detect various analytes. ${ }^{134,137,141}$ However, only a few studies reported the detection of organic pollutants based on AgNPs signal amplification. Previously, the drug diethylstilbestrol was detected on the basis of its ability to amplify the signal of a copper-based MOF $\left[\mathrm{Cu}_{3}(\mathrm{BTC})_{2}\right]$ loaded with a AgNP-based electrochemical immunosensor sensor. ${ }^{160}$ AgNPs not only enhance the conductivity of $\mathrm{Cu}_{3}(\mathrm{BTC})_{2}$ but also immobilize antibodies through $\mathrm{Ag}-\mathrm{NH}_{2}$ bonds. Similarly, clenbuterol was detected on the basis of the stripping peak of melamine-AgNPs without the need for aptamers and enzymes. ${ }^{161}$ The detection process depended on the selective interaction between the adsorbed melamine at the gold electrode surface and the AgNPs capped by melamine through hydrogen bond interactions. Trifluralin was also detected using AgNPs as a signal amplification element and reduced graphene oxide modified by polyethyleneimine (rGO-PEI) as a wide surface polymer matrix. ${ }^{162}$ Recently, we reported an amplification sensor for detecting methylene blue based on gum arabic-capped AgNPs. ${ }^{28}$

\section{AgNP electrochemical sensors based on organic pollutant oxidation/reduction}

Organic pollutants can be detected at AgNP-modified electrodes on the basis of their oxidation or reduction. AgNPs not only increase the electrode surface area but also act as a catalyst for organic pollutant oxidation/reduction. ${ }^{47,113}$ They also have an excellent conductivity, which facilitates electron transfer. ${ }^{106}$ The determination of various organic pollutants based on their electrochemical reduction at AgNP-modified electrodes was reported. For example, AgNP-decorated polyaniline-nanocrystalline organic-inorganic hybrid zeolite (PANI-Nano-ZSM-5)-modified GC was constructed to detect lindane through its irreversible reduction via dissociative electron transfer. ${ }^{163}$ Additionally, $\mathrm{FeS}_{2} / \mathrm{AgNPs} /$ screen-printed carbon electrode, para-sulfonatocalix[6]arene-AgNPs/GC, $\beta-1,4$ poly D-glucosamine-AgNPs/graphite electrode, AgNPs/Au electrode, biomass carbon/ $\mathrm{Cr}_{2} \mathrm{O}_{3} / \mathrm{Ag} / \mathrm{MIP} / \mathrm{GC}$, and stearic acid/AgNPs/GC respectively were previously reported for the detection of acifluorfen, methyl parathion, 4-nitrophenol, 4-nitrotoluene, 
nitrofurazone, and paraoxon, respectively, on the basis of the irreversible reduction of $-\mathrm{NO}_{2}$ to hydroxylamine groups. ${ }^{125,128,164-167}$ Additionally, thiodicarb was detected at an AgNPs/silver solid amalgam electrode, depending on the electrochemical reduction of two symmetric carbonyl groups in the molecule involving four protons and four electrons. ${ }^{168}$ Also, trichloroacetic acid could be detected at maleic acid-AgNPs/GC through its irreversible reduction to dichloroacetic acid. ${ }^{169}$ Moreover, the reduction mechanism was reported for oxazepam detection. $^{170}$

Conversely, several organic pollutants were detected using the oxidation mechanism. For example, carbendazim was determined using a fumed silica@AgNPs/carbon paste electrode (CPE) through its irreversible electrooxidation. ${ }^{171}$ Amikacin sulphate antibiotic was detected through its oxidation at an rGO-AgNPs/Ni foam electrode with high sensitivity. ${ }^{106}$ The incorporation of AgNPs with AuNPs at a gold electrode for superior electrical conductivity was established to assess ciprofloxacin through its irreversible oxidation via two-electron and two-proton transfer. ${ }^{135}$ Furthermore, AgNPs/SWCNT/CPE was used to detect dienestrol through the oxidation of phenolic groups to semiquinone structures via two-electron and twoproton transfer. ${ }^{172}$ For detecting 5-fluorouracil, porphyranAgNPs/CPE was used for drug oxidation via one-proton and one-electron transfer. ${ }^{173}$ The reaction pathway depended on the formation of radical species that deprotonated and produced on the 5-fluorouracil dimer. In a related investigation, rilpivirine showed two oxidation peaks, which may have originated from two $\mathrm{N}$-substituted aniline groups, for its detection at carbon quantum dots/ $\mathrm{NH}_{2}$-fMWCNT/AgNPs/GC. ${ }^{174}$ Pentachlorophenol was also detected at AgNPs-rGO/GC. ${ }^{175}$

Carbamazepine-AgNPs/GC determination was previously reported for orange II and rhodamine B dyes on the basis of their oxidation. For more intense peaks, electron transfer from the dye to the mediator (AgNPs) and then to GC was achieved through a hopping mechanism. ${ }^{176}$ Moreover, oxadiazole/ AgNPs/GC was used to enhance the oxidation of thiourea analyte. ${ }^{129}$ Catechol and hydroquinone were detected electrochemically via two-electron transfer. ${ }^{177}$ Doxorubicin was also oxidized via two-electron and two-proton transfer at poly(chitosan)/AgNPs/GC for its detection using SWV. ${ }^{178}$ Table 3 presents a comparison of the detection of organic pollutants using various AgNP-modified electrodes.

\section{Conclusion and future perspectives}

AgNP-based electrochemical sensors are emerging electroanalytical tools for detecting various organic pollutants with remarkably high sensitivity. This review highlighted the fabrication of AgNP-based electrochemical sensors, electrochemical identification and characterization, and sensing process protocols. Determining organic pollutants using AgNP-based electrochemical sensors has attracted significant focus in this review. Different protocols based on the electrochemical responses of AgNPs and analytes were illustrated for the determination of organic pollutants including pesticides, organic dyes, drugs, mycotoxins and nitro-aromatics. AgNPbased electrochemical sensors thus proved to be efficient replacers of the traditional and optical techniques. Their role in detecting organic pollutants in water is significant for subsequent water treatment. AgNP-based electrochemical sensors are emerging as promising candidates for detecting organic pollutants. They should be developed so that they can be scaled up to commercial applications. On another note, there are many other organic pollutants that should be tested by AgNP-based electrochemical sensors. Moreover, the recently investigated sensing protocols such as electrochemical displacement should be tested for different organic pollutants.

\section{Conflicts of interest}

There are no conflicts to declare.

\section{Notes and references}

1 P. Samanta, A. V. Desai, S. Let and S. K. Ghosh, ACS Sustainable Chem. Eng., 2019, 7, 7456-7478.

2 O. M. Alharbi, R. A. Khattab and I. Ali, J. Mol. Liq., 2018, 263, 442-453.

3 H. S. Jhinjer, A. Singh, S. Bhattacharya, M. Jassal and A. K. Agrawal, J. Hazard. Mater., 2021, 411, 125056.

4 K. Kalaitzidou, A. Zouboulis and M. Mitrakas, J. Environ. Chem. Eng., 2020, 8, 104209.

5 Y. Orooji, R. Akbari, Z. Nezafat, M. Nasrollahzadeh and T. A. Kamali, J. Mol. Liq., 2021, 329, 115583.

6 A. Waheed, N. Baig, N. Ullah and W. Falath, J. Environ. Manage., 2021, 287, 112360.

7 J. Wang, X. Tang, Y. Xu, X. Cheng, G. Li and H. Liang, Environ. Res., 2020, 188, 109833.

8 Q. Liu, Z. Zhao, H. Li, M. Su and S.-X. Liang, Ecotoxicol. Environ. Saf., 2021, 207, 111237.

9 M. Picardo, J. Sanchís, O. Núñez and M. Farré, Chemosphere, 2020, 261, 127888.

10 M. Baccarin, M. A. Ciciliati, O. N. Oliveira Jr, E. T. Cavalheiro and P. A. Raymundo-Pereira, Mater. Sci. Eng., C, 2020, 114, 110989.

11 A. M. Campos, P. A. Raymundo-Pereira, F. H. Cincotto, T. C. Canevari and S. A. Machado, J. Solid State Electrochem., 2016, 20, 2503-2507.

12 T. C. Canevari, P. A. Raymundo-Pereira, R. Landers and S. A. Machado, Eur. J. Inorg. Chem., 2013, 5746-5754.

13 P. A. Raymundo-Pereira, A. M. Campos, T. M. Prado, L. N. Furini, N. V. Boas, M. L. Calegaro and S. A. Machado, Anal. Chim. Acta, 2016, 926, 88-98.

14 P. A. Raymundo-Pereira, A. M. Campos, F. C. Vicentini, B. C. Janegitz, C. D. Mendonça, L. N. Furini, N. V. Boas, M. L. Calegaro, C. J. Constantino and S. A. Machado, Talanta, 2017, 174, 652-659.

15 A. Santhosh, V. Theertha, P. Prakash and S. S. Chandran, Mater. Today: Proc., 2021, 46, 4460-4463. 
16 A. Shankar, V. Kumar, N. K. Kaushik, A. Kumar, V. Malik, D. Singh and B. Singh, Curr. Opin. Green Sustain. Chem., 2020, 3, 100029.

17 F. Mollarasouli, E. Zor, G. Ozcelikay and S. A. Ozkan, Talanta, 2021, 226, 122108.

18 R. Bala, S. Mittal, R. K. Sharma and N. Wangoo, Spectrochim. Acta, Part A, 2018, 196, 268-273.

19 H. Fathima, L. Paul, S. Thirunavukkuarasu and K. G. Thomas, ACS Appl. Nano Mater., 2020, 3, 6376-6384.

20 M. M. Hassan, M. Zareef, T. Jiao, S. Liu, Y. Xu, A. Viswadevarayalu, H. Li and Q. Chen, Food Chem., 2021, 338, 127796.

21 P. Chen, S. Yan, E. Sawyer, B. Ying, X. Wei, Z. Wu and J. Geng, Analyst, 2019, 144, 1147-1152.

22 M. Zahran and A. H. Marei, Int. J. Biol. Macromol., 2019, 136, 586-596.

23 I. Ali, F. Ikram, F. Ahmad, J. Nisar, M. R. Shah, S. Ali, I. I. Althagafi and M. Ateeq, J. Mol. Struct., 2021, 1226, 129306.

24 A. Modrzejewska-Sikorska and E. Konował, J. Mol. Liq., 2020, 302, 112559.

25 P. N. Minh, V.-T. Hoang, N. X. Dinh, O. Van Hoang, N. Van Cuong, D. T. B. Hop, T. Q. Tuan, N. T. Khi, T. Q. Huy and A.-T. Le, New J. Chem., 2020, 44, 7611-7620.

26 M. Zahran, M. El-Kemary, S. Khalifa and H. El-Seedi, Green Process Synth., 2018, 7, 100-105.

27 M. El-Kemary, M. Zahran, S. A. Khalifa and H. R. El-Seedi, Micro Nano Lett., 2016, 11, 311-314.

28 M. Zahran, Z. Khalifa, M. A. Zahran and M. A. Azzem, Electrochim. Acta, 2021, 394, 139152.

29 R. J. Ramalingam, P. Arunachalam, M. S. Amer, Z. A. AlOthman, A. G. Alanazi, M. M. AL-Anazy, H. A. ALLohedan and W. M. Dahan, Intermetallics, 2021, 131, 107101.

30 R. Yadav, H. Saini, D. Kumar, S. Pasi and V. Agrawal, Mater. Sci. Eng., C, 2019, 104, 109984.

31 S. Novak, T. Romih, B. Drašler, G. Birarda, L. Vaccari, P. Ferraris, S. Sorieul, M. Zieba, V. Sebastian and M. Arruebo, Analyst, 2019, 144, 488-497.

32 T. Wang, H. Zhao, X. Zhao, Q. Yang and D. Liu, J. Chem. Eng. Data, 2021, 66, 535-543.

33 A. Arrocha-Arcos, R. Cervantes-Alcalá, G. Huerta-Miranda and M. Miranda-Hernández, Electrochim. Acta, 2017, 246, 1082-1087.

34 A. Arsalan, M. F. Alam, S. F. F. Zofair, S. Ahmad and H. Younus, Spectrochim. Acta, Part A, 2020, 226, 117637.

35 G. C. Beaton, A. J. Bottomley, D. Prezgot, A. Ianoul and K. G. Stamplecoskie, J. Mater. Chem. C, 2020, 8, 10755-10760.

36 Y. Wang, A. Chinnathambi, O. Nasif and S. A. Alharbi, Arabian J. Chem., 2021, 103081.

37 K. R. Aadil, N. Pandey, S. I. Mussatto and H. Jha, J. Environ. Chem. Eng., 2019, 7, 103296.

38 E. I. El-Aswar, S. E.-S. Gaber, M. M. Zahran and A. H. Abdelaleem, Desalin. Water Treat., 2020, 195, 275-285.

39 E. I. El-Aswar, M. M. Zahran and M. El-Kemary, Mater. Res. Express, 2019, 6, 105016.
40 S. Xiang, X. Ma, H. Shi, T. Ma, C. Tian, Y. Chen, H. Chen, X. Chen, K. Luo and L. Cai, ACS Appl. Bio Mater., 2019, 2, 4087-4096.

41 H. Ga'al, H. Fouad, J. Tian, Y. Hu, G. Abbas and J. Mo, Pestic. Biochem. Physiol., 2018, 144, 49-56.

42 C. Cao, J. Huang, Y. Guo, C. N. Yan, J. Xiao, Y. X. Ma, J. L. Liu and W. Z. Guan, Environ. Pollut., 2019, 252, 931-940.

43 C. C. Paramesh, G. Halligudra, V. Gangaraju, M. Shastri, K. Harsha, H. Preetham, D. Rangappa, K. S. Rangappa and P. D. Shivaramu, Res. Surf. Interfaces, 2021, 100005.

44 T. Rasheed, M. Bilal, C. Li, F. Nabeel, M. Khalid and H. M. Iqbal, J. Photochem. Photobiol., B, 2018, 181, 44-52.

45 J. Singh and A. Dhaliwal, Environ. Technol., 2020, 41, 1520-1534.

46 B. Zhang, B. Li and Z. Wang, ACS Sens., 2020, 5, 162-170.

47 M. Zahran, Z. Khalifa, M. A.-H. Zahran and M. A. Azzem, Electrochim. Acta, 2020, 356, 136825.

48 X.-H. Jiang, L.-C. Wang, F. Yu, Y.-C. Nie, Q.-J. Xing, X. Liu, Y. Pei, J.-P. Zou and W.-L. Dai, ACS Sustainable Chem. Eng., 2018, 6, 12695-12705.

49 S. Gai, J. Zhang, R. Fan, K. Xing, W. Chen, K. Zhu, X. Zheng, P. Wang, X. Fang and Y. Yang, ACS Appl. Mater. Interfaces, 2020, 12, 8650-8662.

50 Y. Peng, L. Gautam and S. W. Hall, Chemosphere, 2019, 223, 438-447.

51 I. E. Khalil, T. Pan, Y. Shen and W. Zhang, Inorg. Chem. Commun., 2020, 120, 108170.

52 T. Goessens, S. De Baere, N. De Troyer, A. Deknock, P. Goethals, L. Lens, F. Pasmans and S. Croubels, Environ. Res., 2020, 110366.

53 S. Ghosh and A. Mondal, Colloids Surf., A, 2020, 605, 125335.

54 T. Deosarkar, N. Chandrasekaran and A. Mukherjee, Anal. Chim. Acta, 2021, 1142, 73-83.

55 Y. Li, M. Wan, G. Yan, P. Qiu and X. Wang, J. Pharm. Anal., 2021, 11, 183-190.

56 S. Sarkar and R. Das, Sens. Actuators, B, 2018, 266, 149-159.

57 K. Shrivas, S. Sahu, B. Sahu, R. Kurrey, T. K. Patle, T. Kant, I. Karbhal, M. L. Satnami, M. K. Deb and K. K. Ghosh, J. Mol. Liq., 2019, 275, 297-303.

58 C. Xing, S. Zhong, J. Yu, X. Li, A. Cao, D. Men, B. Wu, W. Cai and Y. Li, J. Mater. Chem. C, 2020, 8, 3838-3845.

59 J. Zhu, W. Ahmad, Y. Xu, S. Liu, Q. Chen, M. M. Hassan and Q. Ouyang, Analyst, 2019, 144, 1167-1177.

60 J. Gu and A. Dichiara, Int. J. Biol. Macromol., 2020, 143, 85-92.

61 M. Jing, H. Zhang, M. Li, Z. Mao and X. Shi, Spectrochim. Acta, Part A, 2021, 119652.

62 N. R. Barveen, T.-J. Wang and Y.-H. Chang, Chemosphere, 2021, 130115.

63 A. Raza, A. Biswas, A. Zehra and A. Mengesha, Forensic Sci. Int.: Synergy, 2020, 2, 240-247.

64 F. Y. Kutsanedzie, A. A. Agyekum, V. Annavaram and Q. Chen, Food Chem., 2020, 315, 126231.

65 T. Wei, T. Dong, Z. Wang, J. Bao, W. Tu and Z. Dai, J. Am. Chem. Soc., 2015, 137, 8880-8883. 
66 F. A. Arris, A. M. Benoudjit, F. Sanober and W. W. A. W. Salim, Multifaceted Protocol in Biotechnology, Springer, 2018, pp. 119-137.

67 B. J. Sanghavi, O. S. Wolfbeis, T. Hirsch and N. S. Swami, Microchim. Acta, 2015, 182, 1-41.

68 F. Canfarotta, J. Czulak, A. Guerreiro, A. G. Cruz, S. Piletsky, G. E. Bergdahl, M. Hedström and B. Mattiasson, Biosens. Bioelectron., 2018, 120, 108-114.

69 S. Uniyal and R. K. Sharma, Biosens. Bioelectron., 2018, 116, 37-50.

70 S. A. Lim and M. U. Ahmed, Introduction to immunosensors, Immunosensors, 2019, pp. 1-20.

71 F. C. Christopher, P. S. Kumar, F. J. Christopher, G. J. Joshiba and P. Madhesh, J. Cleaner Prod., 2020, 122356.

72 S. Datta, L. R. Christena and Y. R. S. Rajaram, 3 Biotech, 2013, 3, 1-9.

73 M. Díaz-González, M. Gutiérrez-Capitán, P. Niu, A. Baldi, C. Jiménez-Jorquera and C. Fernández-Sánchez, TrAC, Trends Anal. Chem., 2016, 77, 186-202.

74 S. Findeiß, M. Etzel, S. Will, M. Mörl and P. F. Stadler, Sensors, 2017, 17, 1990.

75 E. Daems, D. Dewaele, K. Barylyuk, K. De Wael and F. Sobott, Talanta, 2021, 224, 121917.

76 C. Hongxia, H. Ji, L. Zaijun, L. Ruiyi, Y. Yongqiang and S. Xiulan, Sens. Actuators, B, 2019, 298, 126866.

77 F. Li, Z. Yu, X. Han and R. Y. Lai, Anal. Chim. Acta, 2019, 1051, 1-23.

78 G. Vasapollo, R. D. Sole, L. Mergola, M. R. Lazzoi, A. Scardino, S. Scorrano and G. Mele, Int. J. Mol. Sci., 2011, 12, 5908-5945.

79 H. Patel, D. Rawtani and Y. Agrawal, Trends Food Sci. Technol., 2019, 85, 78-91.

80 M. Shen and X. Kan, Electrochim. Acta, 2021, 367, 137433.

81 A.-E. Radi, Int. J. Electrochem., 2011, 2011, DOI: 10.4061/ 2011/863196.

82 Y. Zhang, H. Liu, Z. Yang, S. Ji, J. Wang, P. Pang, L. Feng, H. Wang, Z. Wu and W. Yang, Anal. Methods, 2015, 7, 6213-6219.

83 M. R. Willner and P. J. Vikesland, J. Nanobiotechnol., 2018, 16, 1-16.

84 Y. Lu, X. Liang, C. Niyungeko, J. Zhou, J. Xu and G. Tian, Talanta, 2018, 178, 324-338.

85 J. G. Osteryoung and R. A. Osteryoung, Anal. Chem., 1985, 57, 101-110.

86 A. M. Bond, D. Elton, S.-X. Guo, G. F. Kennedy, E. Mashkina, A. N. Simonov and J. Zhang, Electrochem. Commun., 2015, 57, 78-83.

87 H. Wang, M. Pan, Y. O. Su, S. Tsai, C. Kao, S. Sun and W. Lin, J. Anal. Chem., 2011, 66, 415-420.

88 L. Stojanov, D. Guziejewski, M. Puiu, C. Bala and V. Mirceski, Electrochem. Commun., 2021, 124, 106943.

89 J. M. Pingarrón, J. Labuda, J. Barek, C. M. Brett, M. F. Camões, M. Fojta and D. B. Hibbert, Pure Appl. Chem., 2020, 92, 641-694.

90 V. Mirceski, D. Guziejewski, L. Stojanov and R. Gulaboski, Anal. Chem., 2019, 91, 14904-14910.
91 N. I. Hrastnik, V. Jovanovski and S. B. Hočevar, Sens. Actuators, B, 2020, 307, 127637.

92 K. Kaewket, S. Maensiri and K. Ngamchuea, Colloid Interface Sci. Commun., 2020, 38, 100310.

93 X. Sun, L. Qiao and X. Wang, Nano-Micro Lett., 2013, 5, 191-201.

94 A. Othman, A. Karimi and S. Andreescu, J. Mater. Chem. B, 2016, 4, 7178-7203.

95 D. H. Jo, J. H. Kim, T. G. Lee and J. H. Kim, Nanomedicine, 2015, 11, 1603-1611.

96 J. Fu, X. An, Y. Yao, Y. Guo and X. Sun, Sens. Actuators, B, 2019, 287, 503-509.

97 M. Mahmoudpour, M. Torbati, M.-M. Mousavi, M. de la Guardia and J. E. N. Dolatabadi, TrAC, Trends Anal. Chem., 2020, 115943.

98 S. Anandhakumar, K. Dhanalakshmi and J. Mathiyarasu, Electrochem. Commun., 2014, 38, 15-18.

99 P. Balasubramanian, T. Balamurugan, S.-M. Chen, T.-W. Chen, G. Sharmila and M.-C. Yu, J. Taiwan Inst. Chem. Eng., 2018, 87, 83-90.

100 X. Gao, Y. Gao, C. Bian, H. Ma and H. Liu, Electrochim. Acta, 2019, 310, 78-85.

101 S. Hassani, M. R. Akmal, A. Salek-Maghsoudi, S. Rahmani, M. R. Ganjali, P. Norouzi and M. Abdollahi, Biosens. Bioelectron., 2018, 120, 122-128.

102 B. Jiang, P. Dong and J. Zheng, Talanta, 2018, 183, 114-121.

103 A. Jirasirichote, E. Punrat, A. Suea-Ngam, O. Chailapakul and S. Chuanuwatanakul, Talanta, 2017, 175, 331-337.

104 L. Qiu, L. Qiu, Z.-S. Wu, G. Shen and R.-Q. Yu, Anal. Chem., 2013, 85, 8225-8231.

105 M. S. Randelović, M. Z. Momčilović, J. S. Milićević, R. D. Đurović-Pejčev, S. S. Mofarah and C. C. Sorrel, J. Taiwan Inst. Chem. Eng., 2019, 105, 115-123.

106 N. Sharma, S. P. Selvam and K. Yun, Appl. Surf. Sci., 2020, 512, 145742.

107 M. Wei and J. Wang, Sens. Actuators, B, 2015, 211, 290-296.

108 L. Jiang, I. Santiago and J. Foord, Langmuir, 2020, 36, 6089-6094.

109 J.-F. Lemineur, J.-M. Noël, C. Combellas and F. Kanoufi, J. Electroanal. Chem., 2020, 872, 114043.

110 M. Zahran, Z. Khalifa, M. A.-H. Zahran and M. Abdel Azzem, ACS Appl. Nano Mater., 2020, 3, 3868-3875.

111 K. Torres-Rivero, L. Torralba-Cadena, A. Espriu-Gascon, I. Casas, J. Bastos-Arrieta and A. Florido, Sensors, 2019, 19, 4249.

112 A. Fekry, S. Abdel-Gawad, R. Tammam and M. Zayed, Measurement, 2020, 163, 107958.

113 Z. Khalifa, M. Zahran, M. A. Zahran and M. A. Azzem, RSC Adv., 2020, 10, 37675-37682.

114 D. Martín-Yerga, Biosensors, 2019, 9, 47.

115 A. de la Escosura-Muñiz, M. Maltez-da Costa and A. Merkoçi, Biosens. Bioelectron., 2009, 24, 2475-2482.

116 D. Martín-Yerga, J. Carrasco-Rodríguez, M. B. GonzálezGarcía, F. J. García Alonso and A. Costa-García, Electroanalysis, 2014, 26, 2574-2579. 
117 M. Ghanavati, F. Tadayon and H. Bagheri, Microchem. J., 2020, 159, 105301.

118 M. Zahran, Z. Khalifa, M. A. Zahran and M. A. Azzem, Microchem. J., 2021, 106173.

119 H. Sun, J. Kong, Q. Wang, Q. Liu and X. Zhang, ACS Appl. Mater. Interfaces, 2019, 11, 27568-27573.

120 A. Paul, G. Vyas, P. Paul and D. N. Srivastava, ACS Appl. Nano Mater., 2018, 1, 3600-3607.

121 B. Pérez-Fernández, A. Costa-García and A. de la EscosuraMuñiz, Biosensors, 2020, 10, 32.

122 J. R. Sempionatto, R. K. Mishra, A. Martín, G. Tang, T. Nakagawa, X. Lu, A. S. Campbell, K. M. Lyu and J. Wang, ACS Sens., 2017, 2, 1531-1538.

123 D. M. Stanković, M. Jović, M. Ognjanović, A. Lesch, M. Fabián, H. H. Girault and B. Antić, Microchim. Acta, 2019, 186, 1-8.

124 D. Pang, C. Ma, D. Chen, Y. Shen, W. Zhu, J. Gao, H. Song, X. Zhang and S. Zhang, Org. Electron., 2019, 75, 105374.

125 S. Rani, N. Dilbaghi, S. Kumar, R. S. Varma and R. Malhotra, Inorg. Chem. Commun., 2020, 120, 108157.

126 G. Vyas, S. Bhatt and P. Paul, ACS Omega, 2019, 4, 3860-3870.

127 Y.-C. Wang, Y.-C. Chen, W.-S. Chuang, J.-H. Li, Y.-S. Wang, C.-H. Chuang, C.-Y. Chen and C.-W. Kung, ACS Appl. Nano Mater., 2020, 3, 9440-9448.

128 F. Laghrib, H. Houcini, F. Khalil, A. Liba, M. Bakasse, S. Lahrich and M. El Mhammedi, ChemistrySelect, 2020, 5, 1220-1227.

129 M. R. Moghadam, S. Akbarzadeh and N. Nasirizadeh, Microchim. Acta, 2016, 183, 1069-1077.

130 H. Khosropour, B. Rezaei, P. Rezaei and A. A. Ensafi, Anal. Chim. Acta, 2020, 1111, 92-102.

131 Y.-Q. Xue, H. Zhang, Z.-Y. Han and H. He, J. Mater. Chem. C, 2021, 9, 12566-12572.

132 K. Karaboduk, ChemistrySelect, 2019, 4, 6361-6369.

133 W. Bai, F. Nie, J. Zheng and Q. Sheng, ACS Appl. Mater. Interfaces, 2014, 6, 5439-5449.

134 Y. Gao, B. Feng, L. Miao, Y. Chen and J. Di, Microchem. J., 2020, 157, 104995.

135 J. M. George, R. N. Priyanka and B. Mathew, Microchem. J., 2020, 155, 104686.

136 K. M. Hassan, G. M. Elhaddad and M. AbdelAzzem, Microchim. Acta, 2019, 186, 1-10.

137 D. Hernández, G. Cepriá, F. Laborda and J. R. Castillo, Electroanalysis, 2019, 31, 405-410.

138 G. Kaladevi, S. Meenakshi, K. Pandian and P. Wilson, J. Electrochem. Soc., 2017, 164, B620.

139 M. Salve, A. Mandal, K. Amreen, P. K. Pattnaik and S. Goel, Microchem. J., 2020, 157, 104973.

140 A. L. Suherman, K. Ngamchuea, E. E. Tanner, S. V. Sokolov, J. Holter, N. P. Young and R. G. Compton, Anal. Chem., 2017, 89, 7166-7173.

141 M. Zhou, L. Han, D. Deng, Z. Zhang, H. He, L. Zhang and L. Luo, Sens. Actuators, B, 2019, 291, 164-169.

142 M. Awan, S. Rauf, A. Abbas, M. H. Nawaz, C. Yang, S. A. Shahid, N. Amin and A. Hayat, J. Mol. Liq., 2020, 317, 114014.
143 N. Xia, Z. Chen, Y. Liu, H. Ren and L. Liu, Sens. Actuators, $B, 2017,243,784-791$.

144 L. Hou, Y. Huang, W. Hou, Y. Yan, J. Liu and N. Xia, Int. J. Biol. Macromol., 2020, 158, 580-586.

145 J. Huang, Z. Xie, Z. Xie, S. Luo, L. Xie, L. Huang, Q. Fan, Y. Zhang, S. Wang and T. Zeng, Anal. Chim. Acta, 2016, 913, 121-127.

146 Y. Jiang, J. Cui, T. Zhang, M. Wang, G. Zhu and P. Miao, Anal. Chim. Acta, 2019, 1085, 85-90.

147 H. Jin, H. Guo, X. Gao and R. Gui, Sens. Actuators, B, 2018, 277, 14-21.

148 C. A. Donini, M. K. L. da Silva, R. P. Simões and I. Cesarino, J. Electroanal. Chem., 2018, 809, 67-73.

149 M. Raj and R. N. Goyal, Sens. Actuators, B, 2019, 284, 759-767.

150 M. A. Deshmukh, B.-C. Kang and T.-J. Ha, J. Mater. Chem. C, 2020, 8, 5112-5123.

151 N. Xia, X. Wang, B. Zhou, Y. Wu, W. Mao and L. Liu, ACS Appl. Mater. Interfaces, 2016, 8, 19303-19311.

152 L. Liu, C. Cheng, Y. Chang, H. Ma and Y. Hao, Sens. Actuators, B, 2017, 248, 178-186.

153 S. L. Allen, J. N. Sharma and F. P. Zamborini, J. Am. Chem. Soc., 2017, 139, 12895-12898.

154 W. Chen, H. Wang, H. Tang, C. Yang and Y. Li, Anal. Chem., 2019, 91, 14188-14191.

155 X. Dan, L. Ruiyi, L. Zaijun, Z. Haiyan, G. Zhiguo and W. Guangli, Appl. Surf. Sci., 2020, 512, 145628.

156 M. Roushani, Z. Rahmati, S. Farokhi, S. J. Hoseini and R. H. Fath, Mater. Sci. Eng., C, 2020, 108, 110388.

157 J. Zhang, X. Xu and Y. Qiang, Sens. Actuators, B, 2020, 312, 127964.

158 Y. Jiang, X. Zhang, L. Pei, S. Yue, L. Ma, L. Zhou, Z. Huang, Y. He and J. Gao, Chem. Eng. J., 2018, 339, 547-556.

159 D. Song, Y. Wang, X. Lu, Y. Gao, Y. Li and F. Gao, Sens. Actuators, B, 2018, 267, 5-13.

160 X. Li, J. Miao, Y. Li, L. Liu, X. Dong, G. Zhao, J. Fang, Q. Wei and W. Cao, ACS Appl. Nano Mater., 2019, 2, 8043-8050.

161 P. Miao, K. Han, H. Sun, J. Yin, J. Zhao, B. Wang and Y. Tang, ACS Appl. Mater. Interfaces, 2014, 6, 8667-8672.

162 M. Jafari, M. Hasanzadeh, R. Karimian and N. Shadjou, Microchem. J., 2019, 147, 741-748.

163 B. Kaur, R. Srivastava and B. Satpati, RSC Adv., 2015, 5, 57657-57665.

164 T.-W. Chen, U. Rajaji, S.-M. Chen and R. J. Ramalingam, Ultrason. Sonochem., 2019, 54, 90-98.

165 Y. Bian, C. Li and H. Li, Talanta, 2010, 81, 1028-1033.

166 J. Cheng, Y. Li, J. Zhong, Z. Lu, G. Wang, M. Sun, Y. Jiang, P. Zou, X. Wang and Q. Zhao, Chem. Eng. J., 2020, 398, 125664.

167 A. Kumaravel, M. Murugananthan, R. Mangalam and S. Jayakumar, Food Chem., 2020, 323, 126814.

168 B. G. Lucca, J. M. Petroni and V. S. Ferreira, Electrochim. Acta, 2017, 246, 748-756.

169 R. Bashami, M. T. Soomro, A. N. Khan, E. S. Aazam, I. M. Ismail and M. El-Shahawi, Anal. Chim. Acta, 2018, 1036, 33-48. 
170 A. Khoshroo, L. Hosseinzadeh, A. Sobhani-Nasab, M. RahimiNasrabadi and H. Ehrlich, J. Electroanal. Chem., 2018, 823, 61-66.

171 A. Özcan, F. Hamid and A. A. Özcan, Talanta, 2021, 222, 121591.

172 A. P. Bezerra, A. O. Santos, V. E. Abrantes-Coutinho, E. D. Silva Filho, J. M. Soares, S. S. Castro and T. M. Oliveira, J. Electroanal. Chem., 2021, 880, 114821.

173 L. Bojko, G. de Jonge, D. Lima, L. C. Lopes, A. G. Viana, J. R. Garcia, C. A. Pessôa, K. Wohnrath and J. Inaba, Carbohydr. Res., 2020, 498, 108193.

174 S. Aftab, S. Kurbanoglu, G. Ozcelikay, N. K. Bakirhan, A. Shah and S. A. Ozkan, Sens. Actuators, B, 2019, 285, 571-583.
175 L. Wang, X. Li, R. Yang, J.-J. Li and L.-B. Qu, Food Anal. Methods, 2020, 13, 2050-2058.

176 A. Shah, M. S. Malik, A. Zahid, F. J. Iftikhar, A. Anwar, M. S. Akhter, M. R. Shah, M. A. Zia, M. N. Ashiq and A. H. Shah, Electrochim. Acta, 2018, 274, 131-142.

177 S. M. Sudhakara, M. C. Devendrachari, H. M. N. Kotresh and F. Khan, J. Electroanal. Chem., 2021, 884, 115071.

178 M. Ehsani, J. Soleymani, P. Mohammadalizadeh, M. Hasanzadeh, A. Jouyban, M. Khoubnasabjafari and Y. Vaez-Gharamaleki, Microchem. J., 2021, 106101. 